\title{
Are credit default swaps a sideshow? Evidence that information flows from equity to CDS markets
}

\author{
Jens Hilscher* \\ Joshua M. Pollet ${ }^{\dagger}$ \\ hilscher@brandeis.edu \\ pollet@bus.msu.edu \\ Mungo Wilson \\ mungo.wilson@sbs.ox.ac.uk
}

This version: July 2011

\begin{abstract}
In this paper we provide evidence that equity returns lead credit protection returns at daily and weekly frequencies, while credit protection returns do not lead equity returns. Our results indicate that informed traders are primarily active in the equity market rather than the CDS market. These findings are consistent with standard theories of market selection by informed traders in which market selection is determined partially by transaction costs. We also find that credit protection returns respond more quickly during salient news events (earnings announcement days) compared to days with similarly volatile equity returns. This evidence regarding the response of credit protection returns to news provides support for explanations related to investor inattention.
\end{abstract}

JEL Classification: G12

Keywords: CDS, market segmentation, inattention

\footnotetext{
*International Business School, Brandeis University, 415 South Street, Waltham MA 02453, USA. Phone +1-781-736-2261.

${ }^{\dagger}$ Broad College of Business, Michigan State University, 315 Eppley Center, East Lansing, MI 488241121, USA. Phone +1-517-884-0549.

${ }^{\ddagger}$ Saïd Business School, Oxford University, and Oxford-Man Institute, Park End Street, Oxford OX1 1HP, UK. Phone +44-1865-288-914.

We thank Markit Group for providing us with data on CDS spreads; Denis Gromb, David Hirshleifer, Robert Jarrow, Carol Osler, Neil Pearson, and Mark Seasholes as well as seminar participants at Brandeis University and Aalto University for helpful comments; and Glen Taksler, former head of CDS strategy at Bank of America, for numerous insightful discussions on the institutional details of the CDS market.
} 


\section{Introduction}

Credit default swap (CDS) contracts are derivative contracts that implicitly allow investors to trade credit protection. In the event of a deterioration in credit quality, the buyer of credit protection (default insurance) gains and the seller loses. CDS contracts may represent the most significant and prolific financial innovation of the last two decades: volumes have grown enormously in recent years. Furthermore, after the recent financial crisis, trading in CDS contracts has become controversial and some government regulators have recently advocated a ban on so-called 'naked' long positions in CDS contracts.

If imposing this type of constraint on CDS positions is to be an effective policy, then there must be some unique characteristic of CDS contracts that is not embedded in related securities. By contrast, standard financial theory emphasizes that all derivative securities are exposed to the same fundamental shocks, and consequently, there is no unique informational feature of CDS contracts. More nuanced theory, focusing on the microstructure of related markets, implies that there can be informational disparities across derivative securities associated with the same underlying asset. In particular, if information is revealed in equity markets and CDS spreads adjust passively, either simultaneously or with delay, then there is no case for this type of intervention. Thus, the market location of information revelation is critically important to assess proposed regulatory interventions. Our findings indicate that informed trading occurs predominantly in equity markets and that CDS markets respond with substantial delay. ${ }^{1}$

We analyze the relative information content of the stock return and the return to buying credit protection derived from CDS spreads (the credit protection return). The stock return and the credit protection return are affected by information about the value of the underlying firm. This link is most evident when considering the impact of firm value via the probability of default. For instance, if the probability of default is higher due to a fall in firm value, then return to credit protection is higher as well. Because equity is the most junior claim in the firm's capital structure, if the probability of default is higher, then the equity return declines. So information about firm value generates a negative relation between the equity return and

\footnotetext{
${ }^{1}$ We note that our results relate to the pre-2008 period and are specifically for corporate CDS contracts, not sovereign CDS contracts.
} 
the credit protection return.

Information is reflected in market prices of both securities based on the trading activity of informed traders. We approach the question of relative information content from the perspective of market selection by informed and uninformed traders (e.g. Easley, O'Hara and Srinivas (1998)). If informed traders choose to trade in only one market, we expect that market to reflect the most up-to-date information. We begin by examining equity returns and credit protection returns for cross-market predictability. If credit protection returns lead equity returns, then some information is reflected first in the CDS market (i.e. informed traders are active in this market). Conversely, if equity returns lead credit protection returns, informed traders trade mainly or only in the equity market. We use daily and weekly data for CDS contracts for almost 800 firms for the period 2001-2007 to evaluate these two possibilities. We regress daily and weekly credit protection returns on contemporaneous and lagged equity returns and run the analogous regressions for equity returns.

We find that stock returns predict credit protection returns at horizons of up to several weeks, controlling for lagged returns. In contrast, credit protection returns contain no statistically significant information about future equity returns. Information is reflected first in the equity market and is only subsequently fully reflected in the CDS market. We interpret these results as evidence for the presence of informed traders in the equity market and the general absence of informed traders in the CDS market. These results are also inconsistent with the possibility that CDS trading amplifies shocks in the equity markets via a feedback mechanism because credit protection returns do not predict equity returns.

Easley at al. analyze a model in which there are both informed traders, who seek to profit from their superior private information, and uninformed or liquidity-based traders, whose presence will allow informed traders to trade without revealing their identity. In this setting the two possible equilibria are that "informed traders choose to "pool" and trade in both markets, or to "separate" and trade in only one market". An informed investor chooses a market in order to maximize expected profits and is more likely to trade in a market with (1) high sensitivity of the security to the information that will eventually become public; (2) low transaction costs; and (3) a high proportion of uninformed traders. The relative magnitudes 
of these three factors determines which type of equilibrium holds. Without evidence, there is no means of determining the prevailing type of equilibrium.

Since the CDS market includes large banks as participants, information-based trading in the CDS market is a real possibility. However, even though many firms and institutions participating in this market are sophisticated, a high level of sophistication does not imply that the participants are also informed. For example, a supplier may seek to hedge the tradecredit risk of a customer without superior information about the customer's creditworthiness. Similarly, an insurance company with an extensive corporate bond portfolio might purchase CDS contracts to reduce exposure to a particular bond issuer rather than sell the underlying bonds. Finally, a hedge fund could increase exposure to credit risk as an asset class by trading a portfolio of CDS contracts. In each example, the reason to participate in the CDS market is unrelated to information about expected future changes of the specific firm's CDS spread.

Our findings imply that there is a separating equilibrium in which informed traders participate in the equity market and only liquidity traders participate in the CDS market. From a theoretical perspective, such an equilibrium can be supported by market makers setting bid-ask spreads high enough to deter informed traders from switching to the CDS market in spite of the high fraction of uninformed traders in the CDS market and the high sensitivity of credit protection returns to information. Consistent with this prediction we find that CDS bid-ask spreads are very high, and orders of magnitude higher than the bid-ask spreads of equities.

Furthermore, we expect percentage bid-ask spreads to be higher for securities with higher sensitivity to information. Credit protection is conceptually similar to a put option on the underlying firm value. This intuition follows from the Merton (1974) model of corporate debt in which risky debt is economically equivalent to a portfolio of risk-free debt and a short position in a put on the underlying asset, and hence, risk-free debt is equivalent to risky debt plus a long position in the put. Since a portfolio of a risky bond plus default insurance is also risk-free, holding credit protection is analogous to owning a put on the underlying asset. For firms with better credit ratings, which tend to be far from default, such puts are more sensitive to information about firm value because they are further out of the money.

This intuition is based on the Black-Scholes formula for a European put option. It is 
straightforward to show that the magnitude of the sensitivity of the put option return to the return of the underlying asset becomes larger as the put option moves further out of the money. This sensitivity is equal to the hedge ratio (or delta) of the put option multiplied by the ratio of the underlying asset price to the put option price (leverage). Easley et al. consider a model in which option leverage is held constant while varying option delta. In reality, option leverage grows more rapidly than the magnitude of delta declines as an option moves out of the money.

For informed investors to choose to trade in the equity market, given the higher information sensitivity of CDS contracts, it has to be the case that the percentage bid-ask spreads for CDS contracts are higher for better-rated firms. Consistent with this reasoning, percentage bid-ask spreads on firms' CDS contracts rated A and above are almost three times as high as those rated $\mathrm{BB}$ and below (non-investment grade). This finding is not a priori obvious and provides additional evidence in support of the separating equilibrium.

If a pooling equilibrium ever prevails (informed traders participate in the CDS market and in the equity market), it is more likely to hold for firms with high-risk credit ratings given the bid-ask spreads we observe in the CDS market. We only find very limited evidence that the credit protection return predicts the equity return two days later for firms rated BB and below. However, even for these firms, equity returns still predict credit protection returns quite strongly at both short and long horizons. Furthermore, we do not find any evidence that a pooling equilibrium prevails following events that would plausibly be associated with initial information acquisition by participants in the CDS market, such as large credit protection returns or positive credit protection returns. ${ }^{2}$

In summary, we find strong evidence that informed traders participate only in the equity market and are deterred from trading in the CDS market by high spreads. This finding is broadly consistent with the separating equilibrium of market selection models. It appears that most trading of CDS contracts is primarily motivated by liquidity considerations. This finding undermines the case for a ban on naked long positions in CDS markets.

The length of delay in the adjustment of CDS spreads to publicly available equity return

\footnotetext{
${ }^{2}$ In unreported results, we also do not find evidence of initial information acquisition in the CDS market for negative earnings surprises.
} 
data is puzzling, even in a separating equilibrium, because CDS traders can easily gather information from the equity market. It is possible that using intraday quotes from CDS market makers implies that price data from CDS and equity markets may not be synchronized perfectly. However, we find significant predictability of credit protection returns using equity returns with a time lag of five trading days in daily specifications and analogous predictability with a time lag of four weeks in weekly specifications. Thus, intraday nonsynchronous prices between the two markets does not appear to be a valid explanation for our results.

In the absence of limits to arbitrage, credit protection returns should not be predictable using equity returns at such long horizons. We consider two possible explanations for the delayed response that are not mutually exclusive. First, transaction costs for CDS contracts could be sufficiently high that the predictability based on the midpoint of the quoted CDS spread is not worth exploiting because participants must trade at the relevant bid or ask, and so, what appears to be substantial predictability in our analysis is not actually exploitable. Second, the predictability is evidence of mispricing created by inattentive participants in the CDS market. In this setting, the expected abnormal return gained from informed trading is offset by the risk that the mispricing will move in the wrong direction in the short-term.

We find that the CDS market responds more slowly to news in the equity market for firms with a low number of quotes in the CDS market (a proxy for high transaction costs). In addition, the CDS market responds more rapidly following equity returns that are larger in absolute value. Essentially, it is only necessary to adjust CDS quotes to preclude profitable trading strategies if the equity return is large relative to the CDS bid-ask spread; otherwise, transaction costs deter trading and quotes adjust more slowly. Thus, the evidence suggests that high transaction costs play an important role.

Inattention of CDS market participants to equity markets is another plausible explanation. If traders in the CDS market are motivated by liquidity considerations, and if investor attention is a scarce resource (Della Vigna and Pollet (2007), Barber and Odean (2008), Cohen and Frazzini (2008)) then CDS traders will be less attentive than equity traders to events of common concern. Consistent with this hypothesis, we show that the response of credit protection returns to stock returns is much faster immediately after regular corporate earnings announcements, 
when, presumably, equity and CDS traders are more likely to pay attention (Frazzini and Lamont (2006)). As part of our empirical approach, we construct a placebo sample by matching each earnings announcement to a different day where the equity return for the same firm is of similar magnitude. Comparing our sample of earnings announcements to this placebo sample ensures that the more rapid response following earnings announcements is not due to larger variation in equity returns or potential differences in transaction costs.

These findings provide a counterpoint to the existing literature regarding the role of derivatives markets in determining how information enters prices. Easley et al. (1998), Pan and Poteshman (2006), and Ni, Pan, and Poteshman (2007) provide evidence that stock and option markets are in a pooling equilibrium, in which informed traders choose to trade in both stock and option markets. In more recent work regarding options markets, Muravyev, Pearson, and Broussard (2011) indicate that option prices do not contain any additional information about future stock prices once the current stock price is taken into account. While the equilibrium type must depend on a host of theoretical factors, identifying the equilibrium for a particular pair of markets remains an open empirical question.

Our results are also related to studies of information flow between credit markets and equity markets. Kwan (1996) finds that lagged stock returns are correlated with current bond yield changes, while the opposite is not the case. This evidence is consistent with our findings since the sensitivity of corporate bonds to fundamentals is always much lower than the sensitivity of the associated credit protection or equity. Of these three securities, the bond is the least information-sensitive.

Acharya and Johnson (2007), using data for 79 US firms from 2001 to 2004, "find significant incremental information revelation in the credit default swap market ... only for negative credit news and for entities that subsequently experience adverse shocks." Our results indicate that credit protection returns do not predict equity returns even after conditioning on large credit protection returns or positive credit protection returns. The findings in Table 2 of Acharya and Johnson are confined to a small group of distressed firms classified using ex post, rather than ex ante, measures of rising credit risk or high credit risk. ${ }^{3}$ However, the analogous results

\footnotetext{
${ }^{3}$ In Table 2 of Acharya and Johnson, a firm is classified as having deteriorating credit at a particular
} 
in the same table are not statistically significant using the firm's credit rating at the time the only ex ante measure of credit risk. Indeed, even for junk-rated firms, the only consistent evidence of predictability at both short and long horizons in our analysis is from equity to CDS markets rather than from CDS to equity markets. Thus, the conventional wisdom that trades in CDS markets reflects information is largely incorrect.

The rest of the paper is organized as follows. Section 2 discusses the mechanics of CDS contracts and the resulting credit protection return. Section 3 describes the data on CDS spreads and equity returns. Section 4 presents our main results. Section 5 analyzes the impact of high transaction costs on the relation between equity and CDS markets. Section 6 considers the potential role of investor inattention in the CDS market and section 7 concludes.

\section{The credit protection return}

Our discussion in the introduction analyzes the properties of a hypothetical credit protection contract in which the buyer of protection pays an up-front premium in exchange for a cash payment if and only if the reference bond defaults before the expiration of the contract. The structure of this contract mimics the most basic kind of insurance agreement and has the properties of a put option on the underlying firm value. In practice, this credit protection contract is not traded independently but is embedded within a credit default swap. Our approach is to extract the return to holding credit protection from quoted CDS spreads.

It is important to recognize that this implicit return is economically quite different from the excess return on a corporate bond implied by the identical CDS spreads, as considered by Berndt and Obreja (2010). In particular, the holder of credit protection gains money for a given absolute deterioration in credit quality and the credit protection return is more sensitive to changes in credit quality for firms with better credit ratings. By contrast, the implied return to a corporate bond for the same deterioration in credit quality is negative and is less sensitive

point in time if the credit spread for the firm increases by more than 50 basis points between this point in time and the end of the sample period and a firm is classified as having high credit risk at a particular point in time if the credit spread remains above 100 basis points from this point in time until the end of the sample period. 
to changes in credit quality for firms with better credit ratings. This analysis follows from the observation that credit protection is like an out of the money put option and such puts are more sensitive to information for firms with better credit ratings because they are further out of the money. It may be useful in other contexts to use the implied return to a corporate bond based on CDS spreads if CDS contracts are more liquid or transparent. However, in our context, we are interested in the market location of informed trading and only the credit protection component of the CDS contract is of interest to informed traders.

\subsection{Mechanics of credit default swaps}

In an idealized credit default swap contract, the party buying credit protection agrees to make all payments made by the underlying reference floating rate risky note (trading at par). The party selling protection agrees to make all payments made by a floating rate riskless note with identical maturity (again, trading at par). Hence, both sides of the swap have zero initial value because the two parties are exchanging payments on bonds with the same initial market value (normalized to be $\$ 1$ ).

In the absence of default, the party buying protection pays $Y_{1, t+k}^{r e f}=\pi_{n, t}+Y_{1, t+k}$ and receives $Y_{1, t+k}$ at the end of each period $t+k$ for any $k \in\{0, \ldots, n-1\}$ where $Y_{1, t}$ is the yield to maturity on the 1-period zero coupon default free bond (spot rate) starting at date $t$, $Y_{1, t}^{r e f}$ is the corresponding yield on the 1-period reference bond, and $n$ is the number of periods until expiration of the credit default swap. Thus, the net payment from the perspective of the purchaser absent default is $\left(\pi_{n, t}+Y_{1, t+k}\right)-Y_{1, t+k}$ at the end of period $t+k$, that is, the credit spread on the CDS contract is equal to the default premium in the yield of the reference note, $\pi_{n, t}$. If default occurs in period $j$, the net payment for each period $k$ where $j \leq k<n-1$ is the proceeds from the post-default bankruptcy or renegotiation minus $Y_{1, t+j}$. Essentially, in default the party purchasing protection remits the recovery proceeds while the party selling protection continues to execute all payments associated with the riskless note until the end of the swap contract. ${ }^{4}$

\footnotetext{
${ }^{4}$ In practice, if default occurs the swap terminates prematurely and the party selling protection must deliver the par value of the default free note in exchange for the reference security (or cash equivalent).
} 
Consider a change in the value of the protection buyer's position between $t$ and $t^{\prime}$, where these two points in time are close together so that the intervening cash flows are negligible. For example, $t$ and $t^{\prime}$ are one day apart within the three-month period between payments set for the typical CDS contract. We evaluate this change in value by opening a position at $t$ and closing out the position at $t^{\prime}$ by arranging a new contract on the opposite side (as a seller of protection). The initial value of this long position at $t$ is $V_{t, t}^{p}=0$ but changes at $t^{\prime}$ to $V_{t, t^{\prime}}^{p}$ and the gain or loss is realized by closing the position at $t^{\prime}$ by taking an opposing position with value $V_{t^{\prime}, t^{\prime}}^{p}$. For each swap position we also denote the market value of the constituent legs of the swap. Let $V_{t, t^{\prime}}^{d f}$ be the market value at $t^{\prime}$ of the stream of default free cash flows received by the buyer of protection for a swap opened at $t$ and $V_{t, t^{\prime}}^{r e f}$ is the market value of the corresponding stream of cash flows based on the reference bond paid by the buyer of protection.

$$
\begin{aligned}
V_{t, t^{\prime}}^{p}-V_{t^{\prime}, t^{\prime}}^{p} & =\left(V_{t, t^{\prime}}^{d f}-V_{t, t^{\prime}}^{r e f}\right)-\left(V_{t^{\prime}, t^{\prime}}^{d f}-V_{t^{\prime}, t^{\prime}}^{r e f}\right) \\
& =\left(V_{t^{\prime}, t^{\prime}}^{r e f}-V_{t, t^{\prime}}^{r e f}\right)-\left(V_{t^{\prime}, t^{\prime}}^{d f}-V_{t, t^{\prime}}^{d f}\right) \\
& =V_{t^{\prime}, t^{\prime}}^{r e f}-V_{t, t^{\prime}}^{r e f}
\end{aligned}
$$

This result follows from the fact that the default free floating rate obligations under the contract at $t$ and $t^{\prime}$ are identical, and therefore, the present value of these payments under the opposite contract positions perfectly offset. The profit realized at $t^{\prime}$ to the buyer of protection at $t$ is given by the difference in the present value of payments based on the reference bond induced by the change in the credit spread. This difference is equivalent to the present value of the difference in the credit spread payments associated with the two contract positions.

To calculate the present value of these differential payments, we must consider the term structure of default free bonds and adjust for the possibility that the differential payments will cease due to default. We define $Y_{m, t}$ as the yield to maturity on the $m$-period zero coupon

This arrangement is economically equivalent to the idealized swap contract which never terminates prematurely because the present value of the remaining payments for the default free bond is always equal to par value by construction and the market value of the reference security is the present value of the recovery proceeds. 
default free bond starting at date $t$. We also define $\pi_{k, t}^{h}$ as the credit spread for a hypothetical security that pays 0 at $t+k$ if the reference bond defaults before $t+k$ and 1 at $t+k$ otherwise. Using this hypothetical credit spread, the change in value of the swap is

$$
\begin{aligned}
V_{t, t^{\prime}}^{p}-V_{t^{\prime}, t^{\prime}}^{p} & =V_{t^{\prime}, t^{\prime}}^{r e f}-V_{t, t^{\prime}}^{r e f} \\
& =\sum_{k=1}^{n} \frac{\left(\pi_{n, t^{\prime}}+Y_{1, t+k}\right)-\left(\pi_{n, t}+Y_{1, t+k}\right)}{\left(1+Y_{k, t^{\prime}}+\pi_{k, t^{\prime}}^{h}\right)^{k}} \\
& =\sum_{k=1}^{n} \frac{\pi_{n, t^{\prime}}-\pi_{n, t}}{\left(1+Y_{k, t^{\prime}}+\pi_{k, t^{\prime}}^{h}\right)^{k}} \\
& =\left(\pi_{n, t^{\prime}}-\pi_{n, t}\right) \sum_{k=1}^{n} \frac{1}{\left(1+Y_{k, t^{\prime}}+\pi_{k, t^{\prime}}^{h}\right)^{k}} .
\end{aligned}
$$

\subsection{Calculating returns}

The CDS contract can be recast as a credit protection agreement with an up-front insurance premium equal to the discounted present value of the credit spread at $t$. The premium for this implicit insurance contract is given by

$$
P V\left(\pi_{n, t}\right)=\pi_{n, t} \sum_{k=1}^{n} \frac{1}{\left(1+Y_{k, t}+\pi_{k, t}^{h}\right)^{k}} .
$$

Thus, the return on the implicit insurance contract is the profit from the trades of the protection buyer divided by this implicit premium. 


$$
\begin{aligned}
\frac{V_{t, t^{\prime}}^{p}-V_{t^{\prime}, t^{\prime}}^{p}}{P V\left(\pi_{n, t}\right)} & =\frac{V_{t^{\prime} t^{\prime}}^{r e f}-V_{t, t^{\prime}}^{r e f}}{P V\left(\pi_{n, t}\right)} \\
& =\frac{\left(\pi_{n, t^{\prime}}-\pi_{n, t}\right) \sum_{k=1}^{n} \frac{1}{\left(1+Y_{k, t^{\prime}}+\pi_{k, t^{\prime}}^{h}\right)^{k}}}{\pi_{n, t} \sum_{k=1}^{n} \frac{1}{\left(1+Y_{k, t}+\pi_{k, t}^{h}\right)^{k}}} \\
& =\left(\frac{\pi_{n, t^{\prime}}-\pi_{n, t}}{\pi_{n, t}}\right)\left(\frac{\sum_{k=1}^{n} \frac{1}{\left(1+Y_{k, t^{\prime}}+\pi_{k, t^{\prime}}^{h}\right)^{k}}}{\sum_{k=1}^{n} \frac{1}{\left(1+Y_{k, t}+\pi_{k, t}^{h}\right)^{k}}}\right)
\end{aligned}
$$

We label this return as the credit protection return and it is equal to the percentage change in the quoted CDS spread adjusted by the ratio of two annuity factors. In practice, this ratio will always be close to one relative to the percentage change in the CDS spread. Thus, the credit protection return is well approximated by the percentage change in the credit spread. We use the percentage change in the credit spread as the credit protection return in the empirical analysis below. Further refinements that incorporate the ratio of these annuity factors require additional assumptions regarding recovery rates and generate qualitatively very similar results.

\section{Data description}

We are interested in the links between the equity market and the credit default swap (CDS) market. For this purpose we assemble data on returns for both of these assets.

\subsection{Credit default swap data}

The CDS market is a relatively young market. However, it has grown very quickly and received a lot of attention over the last several years. ${ }^{5}$ CDS contracts have only been available for a

\footnotetext{
${ }^{5}$ See, for example, Blanco, Brennan, and Marsh (2005), Longstaff, Mittal and Neis (2005) and Ericsson, Jacobs, and Oviedo (2009).
} 
large number of firms since the early 2000s. In 2001 the market reached $\$ 1$ trillion of notional value outstanding. It has roughly doubled each year since, reaching $\$ 34$ trillion in 2006 and $\$ 62$ trillion in 2007 . However, in 2008 market size declined to $\$ 39$ trillion. $^{6}$

We obtain our CDS data from Markit Group Limited (Markit). Markit, founded in 2001, uses a network of large partner banks from which they assemble daily CDS spread quotes. According to Markit, "Finance industry professionals who need to view and extract various forms of credit spread data and analytics use the Markit website. ... They typically work for financial institutions such as large commercial banks, insurance companies, asset managers, and credit arbitrage funds." 7

The time period for our data is from January 2001 to December 2007. The number of firms with available data increases from close to 250 names in 2001 to about 650 names in 2005 before stabilizing at that level in 2006 and 2007. We use data for 5-year contracts because these are the most widely traded and the most liquid for United States firms. ${ }^{8}$ This source of data is also used by Han and Zhou (2008), Acharya, Schaefer, and Zhang (2008), and Kapadia and $\mathrm{Pu}(2009)$.

\subsection{Summary statistics}

We collect daily equity market data, quarterly accounting data, and monthly S\&P credit ratings from CRSP and COMPUSTAT. We calculate market capitalization and market leverage based on this information. We also collect CDS bid-ask spread data for 2007 from Datastream since Markit only provides the average of the quotes and the number of quotes.

Table 1 reports summary statistics. The data set contains 782 firms for which we have CDS and equity market data. The average CDS spread is equal to 158 basis points and the average firm has a credit rating of $\mathrm{BBB}$. The wide variation in credit quality is reflected by the inter-quartile range of 42 to 192 basis points for credit spreads and ratings of BB+ to A-. The average firm has 1005 days of available CDS data (approximately 4 years) and $75 \%$ of firms

\footnotetext{
${ }^{6}$ Source: ISDA market survey, www.isda.org.

${ }^{7}$ Markit User Guide (2007).

${ }^{8}$ We include only observations that use the modified restructuring default definition clause since this is the restructuring convention that is most commonly used for U.S. firms.
} 
have more than 2 years of daily spread data.

CDS contracts are predominantly for large firms. The average firm has a market capitalization of $\$ 15$ billion and $75 \%$ of firms have capitalizations greater than $\$ 2.5$ billion. Market leverage, which we calculate as total liabilities divided by total liabilities plus market capitalization has an inter-quartile range of $34 \%$ to $64 \%$, again reflecting the large range of firms with available CDS data.

Table 2 reports percentage bid-ask spreads for CDS contracts for the three groups of firms based on credit rating. The percentage spread is defined as the bid-ask spread for the CDS contract divided by the CDS spread (the midpoint of the bid-ask spread). As indicated in column 1, the average CDS bid-ask spread is very high, and significantly higher than the analogous average bid-ask spread for equities. Indeed, according to Hendershott, Jones, and Menkveld (2010), round trip quoted bid-ask spreads for equities as a percentage of the midpoint are approximately 10 basis points $(0.1 \%)$ for large-cap stocks. For the corresponding credit protection premium, the analogous magnitudes are $7.5 \%$ for junk bonds and $20.4 \%$ for highgrade bonds. Thus, bid-ask spreads for CDS contracts are orders of magnitude higher than for corresponding equities. Based on these differences in the bid-ask spreads between between equity and CDS markets, it is possible that the equilibrium is one in which market makers set CDS bid-ask spreads sufficiently high to deter informed traders from trading in the CDS market.

In addition, column 2 through column 4 of Table 2 indicate that the percentage bid-ask spreads for CDS contracts are considerably larger for firms with lower-risk credit ratings. The average CDS bid-ask spreads for firms rated A and above is approximately three times as high as the average CDS bid-ask spread for firms rated BB and below (non-investment grade). This result provides additional support for an equilibrium that deters informed traders from participating in the CDS market, because it is the CDS contracts for high-grade firms that are most sensitive to information. Table 3 reports summary statistics for equity and credit protection returns. We note that the volatility of credit protection returns is quite similar to the volatility of equity returns. 


\section{Cross-predictability}

We are interested in the location of informed traders in the CDS and equity markets. In this section we examine the location of informed trading by considering whether or not equity returns predict credit protection returns and vice versa. We first examine daily returns and then consider weekly returns.

\subsection{Daily returns}

\subsubsection{Predictability of credit protection returns using equity returns}

We begin by examining the response of credit protection returns to the equity returns of the same firm. We estimate the following specification:

$$
R_{j, C P, t+T}=\beta_{0, j, T}+\beta_{1, T} R_{j, E Q, t}+\beta_{2, T} R_{j, C P, t}+\varepsilon_{t}
$$

The dependent variable, $R_{j, C P, t+T}$, is the credit protection return for firm $j$ over day $t+T$

for $T$ from zero to ten days. The independent variables include $R_{j, E Q, t}$, the equity return for firm $j$ for day $t$, the corresponding credit protection return as a control (if $T>0$ ), and firm fixed effects. We estimate these regressions separately for all firms rated A and above according to their Standard \& Poor long-term credit rating, all firms rated BBB, and BB or below (non-investment grade); $t$-statistics are reported based on standard errors clustered by date.

Panel A of Table 4 reports estimates of the coefficients of $\beta_{1, T}$ with $t$-statistics in parentheses beneath. Credit protection returns are negatively contemporaneously related to equity returns. Increasing the equity return by $1 \%$ is associated with a contemporaneous change in the credit protection return for a typical A-or above-rated issuer of $-0.18 \%$ or 18 basis points (bps), -14 bps for a BBB and -11 bps for a junk-rated issuer, all highly statistically significant. Differences in coefficient magnitudes across the three rating groups are statistically significant at the $1 \%$ level (difference between BBB and A, above) and 5\% level (difference between BBB and BB, below). 
The greater sensitivities for better-rated issuers are consistent with the insight of Merton's (1974) theory of corporate debt as a portfolio of risk-free debt minus a put option on the underlying firm. The specification in equation (1) regresses credit protection returns on equity returns for the same firm. Therefore, the resulting coefficient estimates are actually ratios of sensitivities to the return on the underlying firm, rather than the sensitivity of the credit protection return to the return on the underlying firm. Given the return for the unlevered firm, the sensitivity of the credit protection return to the equity return is the ratio of the sensitivity of the credit protection return to the underlying asset return, $\beta_{C P, V}$ to the sensitivity of the equity return to the underlying asset return, $\beta_{E Q, V}$. Thus, $\beta_{1, T}=\beta_{C P, V, T} / \beta_{E Q, V, T}$ holding all else constant. As a firm moves further from bankruptcy, its credit protection becomes further from the money and the firm's equity more in the money. For such high-grade firms, $\beta_{C P, V}$ is larger in absolute value (more negative) and $\beta_{E Q, V}$ is smaller (positive, but closer to zero). The net effect for the ratio, that is $\beta_{C P, V} / \beta_{E Q, V}$, is larger in absolute value (more negative), and credit protection returns should be relatively more sensitive (stronger negative relation) to equity returns. Hence, the Merton model of corporate debt predicts that credit protection returns should be more sensitive (further from zero) to equity returns for better-rated firms. An analogous argument predicts that equity returns should be less sensitive (closer to zero) to CDS returns for better-rated firms. This intuition is consistent with our results.

The columns to the right of column one in Panel A of Table 4 report the sensitivity of credit protection returns to lagged equity returns, moving from lags of 1 to 10 days. For all three groups, credit protection returns respond negatively to lagged equity returns at horizons of up to five trading days with statistical significance above 1\%. During these first five days, it is also the case that the sensitivity of credit protection returns to equity returns is greater (further from zero) for firms with better credit ratings.

Panel B of Table 4 analyzes cumulative response coefficients for the columns of Panel A. For firms with good credit ratings (A or better), the credit protection return response to a $1 \%$ higher equity return is -60 bps after 5 days compared to -18 bps for the contemporaneous response. Similarly, for firms with a credit rating of BBB the five-day response is -49 bps (contemporaneous -14 bps) and for firms with junk credit ratings (BB or worse) the response 
is $-40 \mathrm{bps}$ (contemporaneous $-11 \mathrm{bps}$ ). These coefficients are plotted in Figure 1. The slope of the cumulative sensitivity is negative and the increase in the absolute magnitude of the response to equity returns over time is similar across the rating groups in percentage terms.

Panel $\mathrm{C}$ of Table 4 considers the statistical significance of this differential response. The regressions test whether or not there is a statistically significant response to equity returns following the contemporaneous response. The independent variables of the regression are unchanged, but the dependent variable is the cumulative return from day $t+1$ to day $t+5$ in column $1, t+2$ to $t+6$ in column $2, t+1$ to $t+10$ in column 3 and $t+2$ to $t+11$ in column 4 . For all three rating groups, the cumulative response from one to five days following the equity return for day $t$ is significant at the $1 \%$ level and we find similar statistical evidence results for the cumulative return from $t+2$ to $t+6$. We consider this alternative window to ensure that the results are not caused only by the differential response to equity returns at $t+1$. The results for the cumulative credit protection response ten days following the equity return, that is, from $t+1$ to $t+10$ are statistically weaker, but match the pattern found for the shorter horizon. $^{9}$

The $t$-statistics used in this context must take into account the autocorrelation induced by using daily overlapping observations of the cumulative credit protection returns as well as the contemporaneous cross-correlation for different firms. We allow for heteroskedasticity and arbitrary contemporaneous correlation across firms by clustering the standard errors by date. In addition, we correct these standard errors to account for autocorrelation in the error structure (see appendix). ${ }^{10}$

The results reported in Table 4 document a delayed response of credit protection returns to equity returns, controlling for lagged credit protection returns and firm fixed effects. At all horizons, the response is larger (more negative) for better-rated issuers and it is statistically significant at horizons of up to 10 days.

\footnotetext{
${ }^{9}$ The coefficient estimates in Panel C differ from those in Panel B because we are using overlapping observations in Panel C.

${ }^{10}$ This method is more conservative than clustering by date or stock. In the empirical specifications that follow, the standard errors computed with either of these methodologies are almost uniformly lower than our standard errors.
} 


\subsubsection{Predictability of equity returns using credit protection returns}

Having established that equity returns predict credit protection returns, we now address the alternative. We switch the dependent variable in the regression to equity return and the credit protection return becomes the independent variable. We include firm fixed effects and control for the lagged equity return when estimating the predictive power of credit protection returns for equity returns. Table 5 reports our results in an identical format to Table 4.

Column 1 of Panel A indicates that the contemporaneous response of the equity return to a $1 \%$ increase in the credit protection return is $-0.033 \%$ or -3.3 bps for an A-rated issuer. The estimates in column 2 and column 3 report similar results. The contemporaneous response to the equity return is -3.9 bps for a BBB-rated issuer and -4.9 bps for a junk-rated issuer. All coefficients are highly statistically significant.

In addition, the pattern and the magnitudes of the coefficients are consistent with the Merton model of corporate debt and the differences in the magnitudes are statistically significant. Following the logic above, the sensitivity of the equity return to the credit protection return is the ratio of the sensitivity of the equity return to the underlying asset return, $\beta_{E Q, V}$ to the sensitivity of the credit protection return to the underlying asset return, $\beta_{C P, V}$. Thus, $\beta_{1, T}=\beta_{E Q, V, T} / \beta_{C P, V, T}$ holding all else constant. As a firm moves further from bankruptcy, its credit protection becomes further from the money and the firm's equity more in the money. For such high-grade firms, $\beta_{C P, V}$ is larger in absolute value (more negative) and $\beta_{E Q, V}$ is smaller (positive, but closer to zero). The net effect is that the ratio $\beta_{E Q, V} / \beta_{C P, V}$ is smaller in absolute value (less negative), and equity returns should be relatively less sensitive (weaker negative relation) to credit protection returns. Thus, the Merton model of corporate debt predicts that equity returns should be less sensitive (closer to zero) to credit protection returns for firms with better credit ratings.

With one possible exception (discussed below), we find no evidence for a delayed response of equity returns to credit protection returns. Our tests for a delayed response in Panel C fail to reject the null hypothesis of no delay for all window lengths and all rating groups. Figure 2 reports the cumulative responses from Panel B. The cumulative responses appear to be roughly flat lines, indicating that all of the equity response occurs immediately. 
The one potential exception is the marginal statistical evidence in Panel A indicating that the credit protection return for junk-rated issuers predicts the equity return two days later. The coefficient estimate is only marginally significant at the $10 \%$ level. Although this estimate could easily be a statistical accident, it is consistent with the possibility that there may be some informed trading in CDS contracts for junk-rated or distressed firms.

We investigate this possibility further by considering this relation following large credit protection returns and positive credit protection returns in Table 6 . We consider these two subsets of observations, because it is possible that these events may be more closely associated with information revelation in the CDS market. However, as the coefficient estimates in column 2 and column 3 indicate, there is no statistical relation between equity returns and lagged credit protection returns at the $5 \%$ level of significance for either subset of observations. Indeed, the coefficient magnitudes and patterns of significance closely mimic the analogous estimates in Table 5 .

\subsection{Weekly returns}

Table 7 and Table 8 replicate the results of Table 4 and Table 5 using weekly, as opposed to daily, returns. All of the patterns documented in the previous subsection are again visible in Table 7 and Table 8 .

In Table 7, credit protection returns are statistically significantly negatively related to contemporaneous equity returns, controlling for firm fixed effects. An increase of $1 \%$ in the weekly equity return is associated with a -44 bps change to the credit protection return for the same week for firms with good credit ratings. The analogous interpretation indicates an impact of -35 bps for BBB and -29 bps for junk issuers. Again, the pattern of the estimated sensitivities across the ratings groups is consistent with the predictions of the Merton model for corporate debt.

Credit protection returns for all rating groups show a highly statistically significant response to the previous week's equity return (controlling for the previous week's credit protection return). For A-rated firms, the response of the credit protection return to the lagged equity return is significant for each of the previous three weeks. For firms with worse credit ratings, 
the response of the credit protection return to the lagged equity return is highly significant for each of the previous four weeks. For each of the first three weeks, the sensitivities are larger in absolute magnitude for high-quality CDS contracts. Figure 3 plots the cumulative coefficients from Panel B. The pattern documents a clear delayed response of credit protection returns to equity returns. The cumulative response of credit protection returns to equity returns after 4 weeks is more than twice the contemporaneous response for all three groups.

Table 8 shows virtually no evidence of a delayed response by equity returns to credit protection returns in weekly data. For almost all combinations of rating group and time period, the estimated equity response is not significantly different from zero (the only exception is a marginally significant response at the $10 \%$ level for junk-rated issuers using the credit protection return lagged by two weeks). The cumulative responses, reported in Panel B and plotted in Figure 4 as flat lines, indicate that there is no cumulative delayed response of equity returns to credit protection returns.

Our conclusion from the daily and weekly evidence is that a firm's equity returns predict its credit protection returns at horizons of up to one month and that the long-run response of credit protection returns to equity returns is several times larger than the contemporaneous response. As predicted, the contemporaneous and cumulative responses of credit protection returns for better-rated issuers are larger (further from zero) than the analogous responses for worse-rated issuers. There is no substantial evidence that credit protection returns predict equity returns on a daily or weekly basis.

\section{Transaction costs}

The findings in Section 4 indicate that there is a separating equilibrium in which informed investors choose to be active primarily in the equity market. Based on the theory of market selection, this equilibrium is supported by market makers setting bid-ask spreads high enough to deter informed traders from switching to the CDS market, particularly for better-rated issuers. The evidence in Table 2 (discussed earlier) regarding percentage bid-ask spreads for CDS contracts is consistent with this theory because these bid-ask spreads are orders of mag- 
nitude larger than the bid-ask spreads for equities and CDS bid-ask spreads are considerably larger for better-rated firms.

Since transaction costs must play a role in sustaining the observed separating equilibrium, it is quite possible that these same costs are also at least partly responsible for the delayed response of credit protection returns to equity returns. Intuitively, if transaction costs are sufficently large to deter informed trading, they may also be sufficiently large to make it difficult to profit from the predictability of the midpoint of the CDS quotes. Only if the equity return is large relative to the CDS bid-ask spread does it become necessary for CDS market makers to adjust quotes. Hence, high transaction costs will slow the adjustment of CDS spreads to information revealed in equity markets.

There are two testable predictions that follow from this analysis. First, credit protection returns should adjust more slowly to equity returns if there is low depth for a CDS contract (a proxy for high transaction costs), holding all else constant. Second, credit protection returns should adjust more quickly if the equity return is large in absolute value, holding all else constant. This second prediction follows from the intuition that important information revealed in equity markets would lead to profitable trading strategies in CDS markets unless CDS quotes adjust in spite of high transaction costs. ${ }^{11}$ We measure the speed of the CDS response using the fractional response: the fraction of the credit protection return from $t$ to $t+11$ that occurs immediately at $t$ due to the equity return at $t$. If CDS quotes change quickly (slowly), then the fractional response will be high (low).

The evidence in Table 9 is consistent with both predictions. The fractional response is regressed on different sets of variables including an indicator for low $\operatorname{depth}^{12}$ and the absolute value of the equity return at $t$. The specification in column 1 indicates that low depth for a CDS contract, i.e., high transaction costs are associated with a significantly lower fractional response. The coefficient estimate for the absolute value of equity returns in column 2 indicates

\footnotetext{
${ }^{11}$ This prediction is also consistent with investor inattention. A larger equity return for a particular firm could increase investor attention to the related CDS contracts as well. We discuss inattention in the next section.

${ }^{12}$ Firms in the lowest quartile of the distribution for the number of independent quotes in a calendar quarter are defined to have low market depth.
} 
that larger returns are significantly positively related to the fractional response. Column 3 indicates that neither of these statistical relations is subsumed by the other. In column 4, the specification in column 2 is augmented with an interaction term using the indicator for observations with the absolute value of the equity return on date $t$ in the top $10 \%$ of the distribution. The estimates show that the marginal relation between this absolute value and the fractional response is nonlinear. The marginal relation is more than four times greater if the equity return is large in magnitude and this difference is statistically significant. Column 5 indicates that this nonlinear relation is not due to the impact of low depth on the fractional response.

Since all of these specifications include firm fixed effects, these results are not due to crosssectional variation associated with firm-specific characteristics. In addition, the patterns of statistical significance for the coefficients of interest remain unchanged if time fixed effects are also included in the specifications or if each rating group is analyzed separately. Of course, there could be behavioral explanations for these results but transaction costs provide a straightforward explanation for the impact of depth and size of equity return on the fractional response. Therefore, transaction costs contribute to the delayed response documented in the previous section.

\section{Inattention and earnings announcements}

Inattention is another potential explanation for the slow adjustment of CDS spreads to information in equity returns. We analyze this hypothesis by examining responses around earnings announcements. Since CDS traders are predominantly trading for non-fundamentals-based reasons, they may not be paying close attention to developments in equity markets. If attention increases around earnings announcements, as several studies have argued, including Frazzini and Lamont (2006), then we should observe a more rapid response of credit protection returns to equity returns around these times.

In Table 10 we report typical earnings surprises and the associated typical credit protection return and the typical equity return. Earnings surprises are calculated as follows: actual 
earnings per share minus median analyst forecast from I/B/E/S all scaled by market price per share. We sort all announcements into one of ten groups from lowest (group one) to highest (group 10). The lowest three groups all contain negative mean earnings surprises, group four has a zero mean earnings surprise, and so on. The average earnings surprise ranges from $-1.9 \%$ of price per share for group 1 compared to $1 \%$ of price per share for group 10 .

Panel B of Table 10 shows the average credit protection return for each group in the window from two days before the announcement to 2 days after. Credit protection returns are negatively related to the magnitude of the earnings surprise and the difference in the average credit protection return of $-3.6 \%$ between the top earnings surprise group and the bottom earnings surprise group is statistically significant.

Equity returns during the same window around the earnings announcement are reported in Panel $\mathrm{C}$ of Table 10. The obvious inference is that equity returns monotonically increase across groups one to ten, that is, the opposite of the pattern for credit protection returns. In addition, equity returns are moderately larger in magnitude than the corresponding credit protection returns. The average response for the lowest group is $-3.2 \%$ versus $3.7 \%$ for the highest group. The difference between these two groups, $6.8 \%$, is statistically significant.

Table 11 compares credit protection return and equity return cross-responses outside and during earnings announcements using specifications analogous to those in Table 4 . The contemporaneous response to a $1 \%$ equity return on a non-announcement day is -13.6 bps versus -21.0 for an earnings announcement day. The next day responses are about the same, at -12.9 bps and -12.4 bps respectively, and are both statistically significant. The subsequent credit protection response $(t+2$ to $t+6)$ is 25.5 bps for non-announcement days versus 16.5 bps for announcement days, and this pattern holds at longer horizons: from $t+2$ to $t+11$ the non-announcement day response is -34.8 bps compared to the announcement day response of -21.3 bps. The delayed credit protection response is more than $50 \%$ larger (further from zero) for non-announcement days compared to announcement days even though the initial response on day $t$ (or $t$ and $t+1$ ) is larger for announcement days.

In addition, earnings announcement equity returns have greater explanatory power for the contemporaneous and subsequent-day CDS return: the $R^{2}$ on a typical non-announcement day 
is $0.5 \%$ for the contemporaneous response and about the same for the next day, whereas the $R^{2}$ is $3.2 \%$ for day $t$ and $1.6 \%$ on day $t+1$ whenever day $t$ is an announcement day. We conclude that credit protection returns are more sensitive to equity returns around earnings announcements and that CDS contracts respond to news affecting equity prices more quickly. Our evidence is consistent with CDS traders who only pay attention to equity returns at certain times of high salience, and therefore pay less attention at other times.

If CDS participants pay attention to equity markets during earnings announcements, CDS prices should also 'catch up' with recent developments in equity markets more rapidly at these times. Intuitively, CDS traders check their trading screens for equity price developments in the recent past and adjust their prices on earnings announcement days. The last two columns of Panel A show that the response of the credit protection return on day $t$ to cumulative equity returns from $t-5$ to $t-1$ or from $t-6$ to $t-2$ are greater on earnings announcement days $(-0.12 \%$ and $-0.10 \%$ respectively) compared to non-announcement days $(-0.07 \%$ and $0.05 \%$ respectively). The differences are statistically significant with $t$-statistics of 2.7 and 3.4 respectively.

Panel B shows the sensitivity of equity returns to credit protection returns during and outside earnings announcements. The contemporaneous relation is large and significant for both announcement and non-announcement days, but the lagged response is essentially zero in either case. The lagged response is neither statistically significant nor does it explain a meaningful amount of the equity return variance. There is a higher correlation during earnings announcements, but very little evidence of a slow response.

There is also no evidence that credit protection returns lead equity returns ahead of earnings announcements. If some informed investors possessed superior information about an upcoming earnings announcement and choose to exploit it in the CDS market, we would expect to see credit protection returns during the $(t-5, t-1)$ and $(t-6, t-2)$ intervals predict date $t$ equity returns. The lack of such predictability means that there is no support for the hypothesis of informed trading around earnings announcements in CDS markets.

Table 12 reports the results from a more specific test of the inattention explanation. Again, we use the fractional response, the fraction of the credit protection return response from $t$ to 
$t+11$ that occurs immediately at $t$ due to the equity return at $t$, to measure the speed of the credit market response to information in the equity market. We compare the fractional response for earnings announcement days to the analogous response for non-announcements days. We conduct this comparison between earnings announcement days and the entire baseline sample used in Table 11 as well as between earnings announcement days and a placebo group of non-announcement days chosen to closely mimic the firm characteristics and equity returns on announcement days. Since announcement days usually have more volatile equity returns, we need to make sure it is not just the difference in magnitude of the equity return generating the difference in the fractional response. Specifically, for each earnings announcement we find four equity returns for the same issuer that are matched on equity return magnitude and lie outside a $(t-15, t+15)$ window around earnings announcements.

The first column of Table 12 shows that the fraction of the response from $t$ to $t+11$ due to the response on day $t$ (the contemporaneous response) is $16.5 \%$ for ordinary days versus $19.1 \%$ for announcement days and the difference of $2.6 \%$ between these estimates is statistically significant at the $1 \%$ level. Based on these estimates, the fractional response is $15.7 \%$ larger following earnings announcements than the response for ordinary days. The comparison of earnings announcement days to the placebo days leads to a slightly smaller estimated difference, as expected, of $17.1 \%$ for matching non-announcement days versus $19.1 \%$ for announcement days; the difference between these estimates is $2.0 \%$ and remains statistically significant with a $t$-statistic of 4.4. Using the placebo sample as the control group, the fractional response is $11.2 \%$ larger following earnings announcements, and so, the difference remains highly economically significant.

The findings indicate that the fraction of the total response of credit protection returns occurring on the first day is greater on announcement days than on other days. ${ }^{13}$ By construction, the placebo sample contains observations matched by firm and by equity return magnitude to the earnings announcement sample, and therefore, transaction costs are similar for the two groups. Since transaction costs do not vary substantially across these groups,

\footnotetext{
${ }^{13}$ In addition to using the matching procedure for the placebo sample, we could also directly incorporate the determinants of the fractional response shown to be statistically significant in Table 9 . We find that including these controls does not affect the patterns of statistical significance in Table 12 .
} 
transaction costs cannot explain these findings. The likely explanation for the results is the fraction of traders paying attention.

Credit protection returns respond more strongly and more quickly at times of high salience, when CDS market participants are more likely to be paying attention, than at other times. In consequence, it must also be the case that CDS market participants are not normally particularly attentive to events in the underlying equity markets and investor inattention in CDS markets likely contributes to the delayed response documented in Section 4.

\section{Conclusion}

For a large representative sample of US listed firms, credit protection returns respond sluggishly to equity returns, but equity returns do not respond sluggishly to credit protection returns. As a corollary, it is very doubtful that informed speculators with information about corporate securities have a great impact on prices through trading in the CDS market. Consequently, calls to regulate the CDS market, based on the belief that informed trading in the CDS market is destabilizing, are not well-founded.

Our findings are entirely consistent with the choice-of-market theory of Easley et al. (1998). The evidence is consistent with a separating equilibrium that is supported by high CDS transaction costs. In this equilibrium informed traders primarly participate in the equity market and only liquidity traders participate in the CDS market. Moreover, since proxies for transaction costs associated with CDS contracts increase the delayed response to equity returns, the evidence is consistent with transaction costs explaining why informed traders choose to participate predominantly in equity markets.

This evidence is complementary to the results in Pan and Poteshman (2006) and Ni et al. (2007) for options markets. Geanakoplos (2009) has argued that CDS trading has exacerbated economic volatility following a period of deleveraging, since pessimists would have a way of allowing their views to impact equity prices, with, in his model, consequent real effects. However, we doubt that CDS trading on its own can have as much of an impact as short selling of equity, especially given the absence of evidence that informed traders prefer CDS markets to 
equity markets even when trading in the securities of distressed firms.

In contrast to the previous literature, we also show that the delayed response is not as prevalent around earnings announcements. Such a response is consistent with inattention by CDS traders on non-announcement days. This finding is exactly what we would anticipate if CDS transactions are primarily motivated by hedging or liquidity considerations. 


\section{A Appendix}

This appendix discusses the standard error correction employed in Table 4 Panel C, Table 5 Panel C, and Table 11.

Let $X$ be the matrix of regressors, $\theta$ the vector of parameters, and $\varepsilon$ the vector of errors. The panel has $T$ periods and $J$ stocks. Under the appropriate regularity conditions, $\sqrt{\frac{1}{T}}(\hat{\theta}-$ $\theta)$ is asymptotically distributed $N\left(0,\left(X^{\prime} X\right)^{-1} S\left(X^{\prime} X\right)^{-1}\right)$ where $S=\Gamma_{0}+\sum_{q=1}^{\infty}\left(\Gamma_{q}+\Gamma_{q}^{\prime}\right)$ and $\Gamma_{q}=E\left[\left(\sum_{k=1}^{K} X_{k t} \varepsilon_{k t}\right)^{\prime}\left(\sum_{k=1}^{K} X_{k t-q} \varepsilon_{k t-q}\right)\right]$. The matrix $\Gamma_{0}$ captures the contemporaneous covariance, while the matrix $\Gamma_{q}$ captures the covariance structure between observations that are $q$ periods apart. While we do not make any assumptions about contemporaneous covariation, we assume that $X_{j t}^{\prime} \varepsilon_{j t}$ follows an autoregressive process given by $X_{j t}^{\prime} \varepsilon_{j t}=\rho X_{j t-1}^{\prime} \varepsilon_{j t-1}+\eta_{j t}^{\prime}$ where $\rho<1$ is a scalar and $E\left[\left(\sum_{k=1}^{K} X_{j t-q} \varepsilon_{j t-q}\right)^{\prime}\left(\sum_{k=1}^{K} \eta_{j t}\right)\right]=0$ for any $q>0$.

These assumptions imply $\Gamma_{q}=\rho^{q} \Gamma_{0}$ and therefore, $S=[(1+\rho) /(1-\rho)] \Gamma_{0}$. (Derivation and details are in DellaVigna and Pollet, 2007) The higher the autocorrelation coefficient $\rho$, the larger the terms in the matrix $S$. Since $\Gamma_{0}$ and $\rho$ are unknown, we estimate $\Gamma_{0}$ with $\frac{1}{T} \sum_{t=1}^{T} X_{t}^{\prime} \hat{\varepsilon}_{t} \hat{\varepsilon}_{t}^{\prime} X_{t}$ where $X_{t}$ is the matrix of regressors and $\hat{\varepsilon}_{t}$ is the vector of estimated residuals for each cross-section. We estimate $\rho$ from the pooled regression for each element of $X_{j t}^{\prime} \hat{\varepsilon}_{j t}$ on the respective element of $X_{j t-1}^{\prime} \hat{\varepsilon}_{j t-1}$. 


\section{References}

[1] Acharya, Viral V. and Timothy C. Johnson, 2007, "Insider trading in credit derivatives", Journal of Financial Economics, Vol. 84, 110-141.

[2] Acharya, Viral V., Stephen Schaefer, and Yili Zhang, 2008, "Liquidity Risk and Correlation Risk: A Clinical Study of the General Motors and Ford Downgrade of May 2005", working paper, London Business School and NYU Stern School of Business.

[3] Barber, Brad and Terrence Odean, 2008, "All that glitters: The effect of attention and news on the buying behavior of individual and institutional investors", Review of Financial Studies, Vol. 21, 785-818.

[4] Berndt, Antje, and Iulian Obreja, 2010, "Decomposing European CDS Returns", Review of Finance, Vol. 14, 189-233.

[5] Blanco, Roberton, Simon Brennan, and Ian W. Marsh, 2005, "An Empirical Analysis of the Dynamic Relation between Investment-Grade Bonds and Credit Default Swaps", Journal of Finance, Vol. 60, 2255-2281.

[6] Cohen, Lauren and Andrea Frazzini, 2008, "Economic links and predictable returns", Journal of Finance, Vol. 63, 1977-2011.

[7] Collin-Dufresne, Pierre and Robert S. Goldstein, 2001, "Do Credit Spreads Reflect Stationary Leverage Ratios?", Journal of Finance, Vol. 56, 1929-1957.

[8] DellaVigna, Stefano and Joshua M. Pollet, 2007, "Demographics and industry returns," American Economic Review, 97, 1667-1702.

[9] Easley, David, Maureen O'Hara and P. S. Srinivas, 1998, "Option volume and stock prices: Evidence on where informed traders trade", Journal of Finance, Vol. 53, 431-465.

[10] Ericsson, Jan, Kris Jacobs, and Rodolfo Oviedo, 2009, "The Determinants of Credit Default Swap Premia", Journal of Financial and Quantitative Analysis, Vol. 44, 109-132.

[11] Fitch Ratings, 2003, "Credit Products Special Report: Fitch Examines Effect of 2003 Credit Derivatives Definitions", www.fitchratings.com.

[12] Frazzini, Andrea and Owen Lamont, 2006, "The earnings announcement premium and trading volume", NBER working paper no. 13090.

[13] Geanakoplos, John, 2009, "The leverage cycle", Cowles foundation discussion paper, Yale University.

[14] Han, Song and Hao Zhou, 2008, "Effects of Liquidity on the Nondefault Component of Corporate Yield Spreads: Evidence from Intraday Transactions Data", Finance and Economics Discussion Series, Federal Reserve Board, Washington, D.C.

[15] Hendershott, Terrence, Charles M. Jones, and Albert J. Menkveld, 2010, "Does algorithmic trading improve liquidity?" Journal of Finance, forthcoming. 
[16] Kapadia, Nikunj and Xiaoling Pu, 2009, "Limited Arbitrage between Equity and Credit Markets," working paper, Isenberg School of Management, University of Massachusetts, and Kent State University.

[17] Kwan, Simon H., 1996, "Firm-Specific Information and the Correlation Between Individual Stocks and Bonds," Journal of Financial Economics, Vol. 40, 63-80.

[18] Longstaff, Francis A., Sanjay Mithal, and Eric Neis, 2005, "Corporate Yield Spreads: Default Risk or Liquidity? New Evidence from the Credit Default Swap Market", Journal of Finance, Vol. 60, 2213-2253.

[19] Markit Group Limited, 2007, "Markit.com CDS and ABS User Guide Version 12.1," August 2007, www.markit.com.

[20] Merton, Robert C., 1974, "On the pricing of corporate debt: the risk structure of interest rates" Journal of Finance, Vol. 29, 449-470.

[21] Muravyev, Dmitriy, Neil D. Pearson and John Paul Broussard, 2011, "Is There Price Discovery in Equity Options?" University of Illinois, mimeo.

[22] Ni, Sophie X., Jun Pan and Allen M. Poteshman, 2007, "The information in option volume for future volatility", Journal of Finance, Vol. 63, 1059-1091.

[23] Pan, Jun and Allen M. Poteshman, 2006, "The information in option volume for future stock prices", Review of Financial Studies, Vol. 19, 871-908.

[24] Taksler, Glen, Jeffrey A. Rosenberg, Ward Bortz, and Xiaodong Zhu, Bank of America, Credit Strategy Research, 2007, "Credit Default Swap Primer," Third Edition. 
Figure 1: Credit protection response to the equity return (daily)

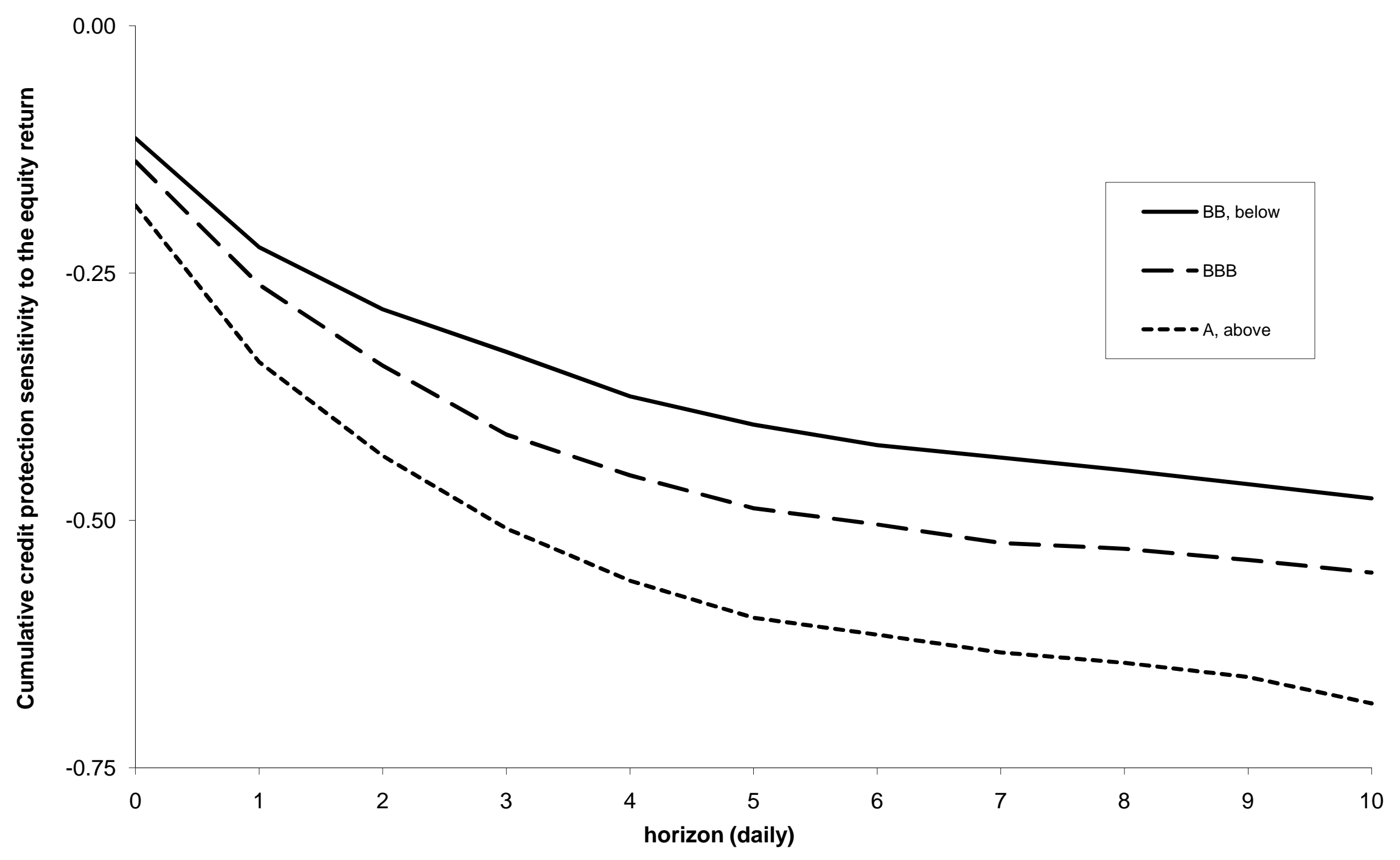


Figure 2: Equity response to the credit protection return (daily)

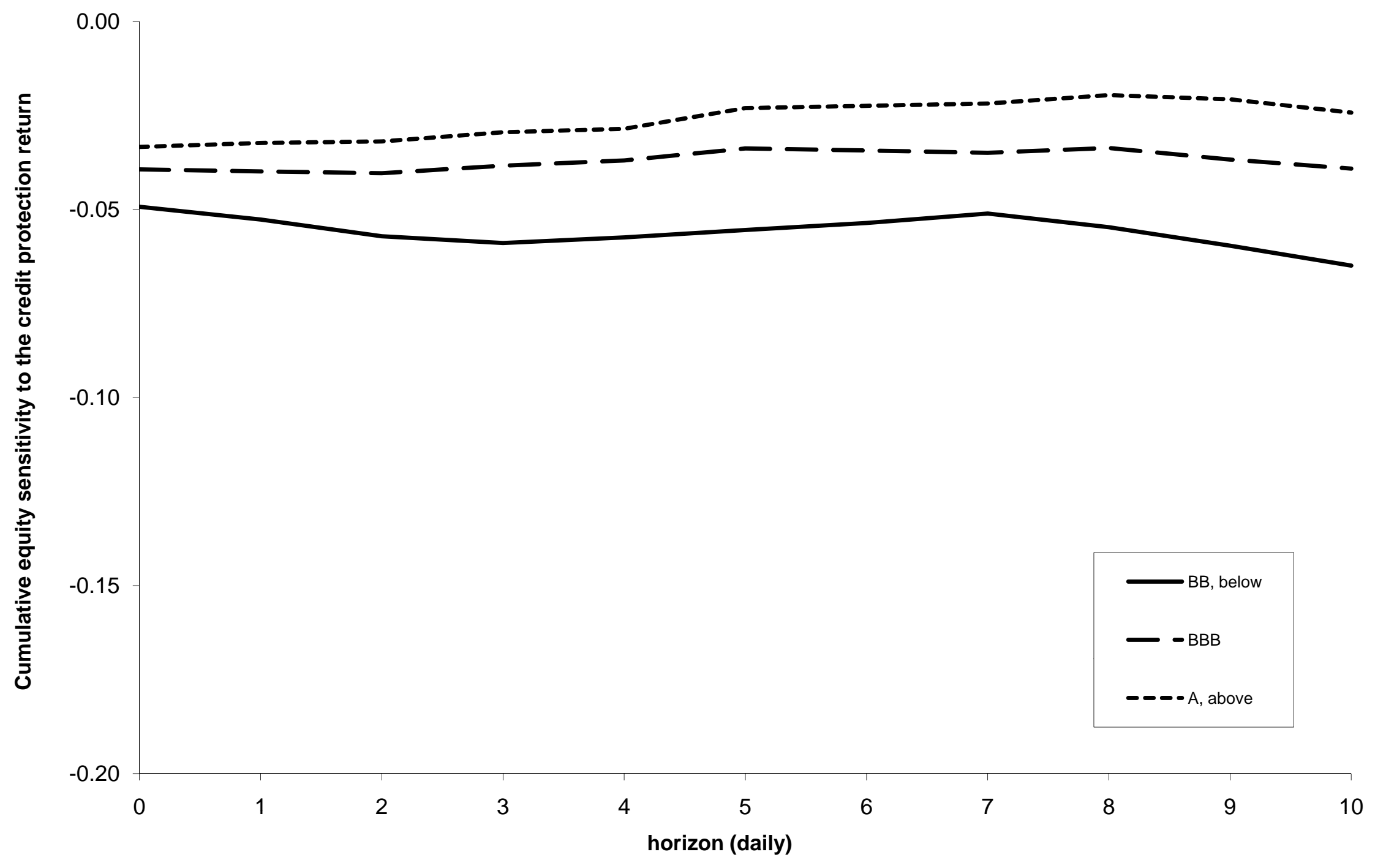


Figure 3: Credit protection response to the equity return (weekly)

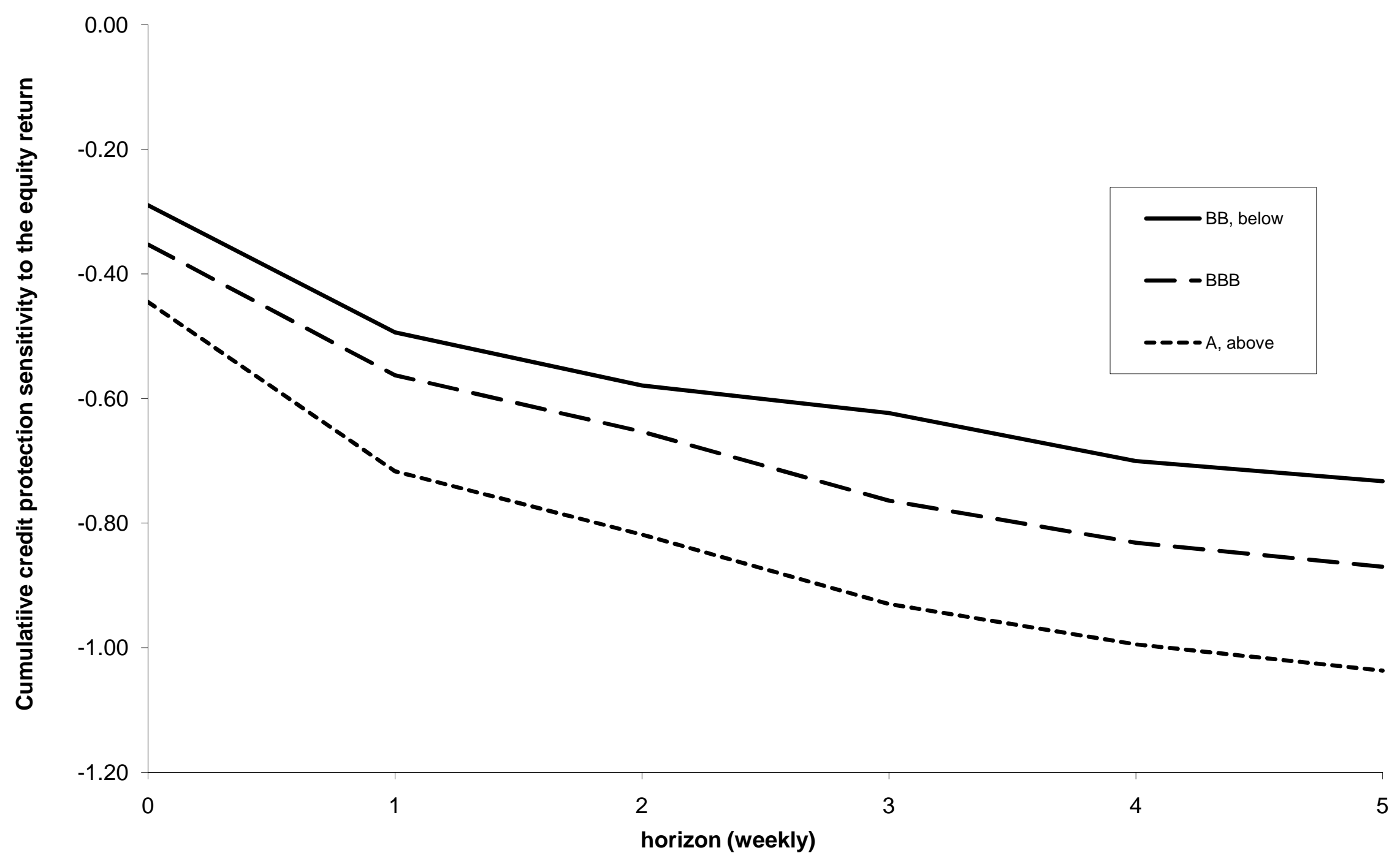


Figure 4: Equity response to the credit protection return (weekly)

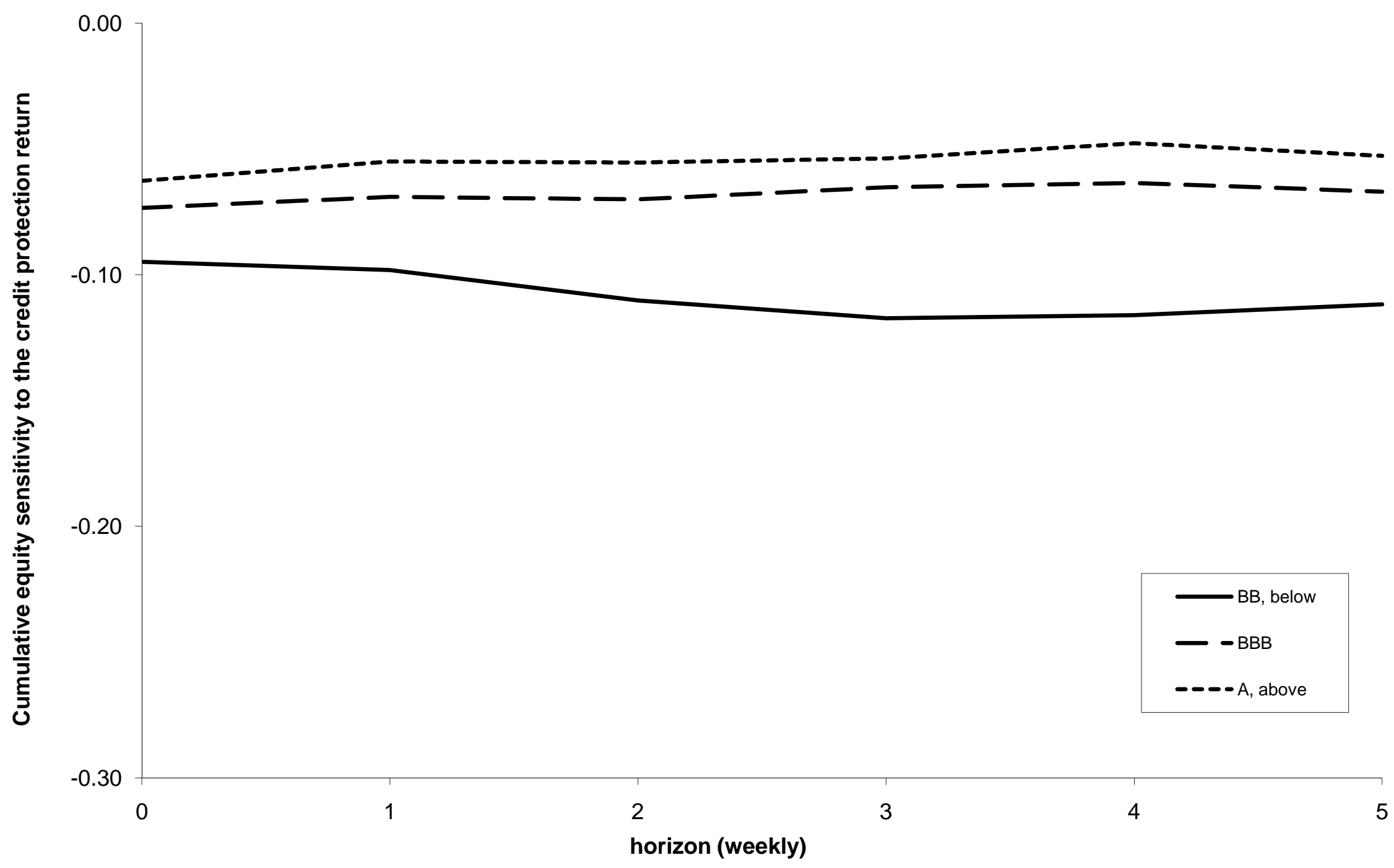




\section{Table 1: Summary statistics}

This table reports summary statistics for firms with CDS spread data from 2001 to 2007. We report these statistics by averaging within firm and then across firms, including only days with available spread observations, equity returns and S\&P credit rating for firms with CDS spread data from 2001 to 2007. CDS spread is average 5 year spread (in basis points), \# days is number of spread observations, market equity capitalization is reported in million USD, leverage is total liabilities divided by the sum of total liabilities and market equity, rating is average S\&P credit rating.

\begin{tabular}{lccccc}
\hline & CDS spread & \# days & market equity & leverage & rating \\
\hline Mean & 158 & 1,005 & 14,987 & 0.49 & BBB \\
Std. dev. & 238 & 533 & 32,694 & 0.21 & - \\
25th percentile & 42 & 532 & 2,489 & 0.34 & A- \\
75th percentile & 192 & 1,475 & 13,684 & 0.64 & BB+ \\
Number of firms: 782 & & & & & \\
\hline
\end{tabular}

Table 2: CDS contract bid-ask spreads

This table reports summary statistics for percentage bid-ask spreads for CDS contracts. Percentage spread is defined as the bid-ask spread divided by the CDS spread (the midpoint of the bid-ask spread). Data is from Datastream and is for 2007.

\begin{tabular}{lcccc}
\hline \multicolumn{5}{c}{ Percentage bid-ask spread } \\
\hline & overall & A, above & BBB & BB, below \\
\hline Mean & $13.9 \%$ & $20.4 \%$ & $12.6 \%$ & $7.5 \%$ \\
Std. dev. & $10.1 \%$ & $11.2 \%$ & $7.8 \%$ & $6.9 \%$ \\
\hline
\end{tabular}

Table 3: Credit protection and equity return summary statistics

This table reports summary statistics for daily equity returns and credit protection returns (in percent). To control for outliers, returns are winsorized at the $0.1 \%$ and the $99.9 \%$ levels.

\begin{tabular}{lcccc}
\hline & Overall & A, above & BBB & BB, below \\
\hline \multicolumn{5}{c}{ Equity returns } \\
\hline Mean & 0.05 & 0.05 & 0.05 & 0.06 \\
Std. dev. & 2.02 & 1.71 & 1.90 & 2.60 \\
25th percentile & -0.88 & -0.79 & -0.86 & -1.15 \\
75th percentile & 0.96 & 0.86 & 0.95 & 1.22 \\
\hline \multicolumn{5}{c}{ Credit protection returns } \\
\hline Mean & 0.05 & 0.07 & 0.04 & 0.05 \\
Std. dev. & 3.82 & 4.01 & 3.60 & 3.92 \\
25th percentile & -0.53 & -0.58 & -0.52 & -0.46 \\
75th percentile & 0.30 & 0.34 & 0.28 & 0.30 \\
Number of observations & 793,144 & 274,323 & 342,219 & 176,602 \\
\hline
\end{tabular}


Table 4: Response of the credit protection return to the equity return (daily)

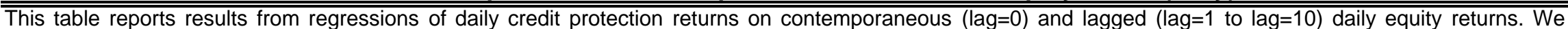
group observations into three groups using monthly S\&P credit rating. Regressions include firm fixed effects; to control for outliers, returns are winsorized at the $0.1 \%$ and the $99.9 \%$ levels. Panel A reports direct effects. We control for autocorrelation in the credit protection return by including the lagged credit protection return. Panel B reports cumulative effects which are calculated as the sum of the direct effects in Panel A. Panel C reports regressions of cumulative 5-day and 10day credit protection returns on current equity returns, controlling for current credit protection returns. Standard errors are adjusted for heteroskedasticity and clustered by date. To control for overlapping observations in Panel C, standard errors are also adjusted for autocorrelation. The t-statistics are reported in parentheses; ${ }^{\star \star}$ denotes significance at $1 \%$ and ${ }^{*}$ denotes significance at $5 \%$.

\begin{tabular}{|c|c|c|c|c|c|c|c|c|c|c|c|}
\hline time period & 0 & 1 & 2 & 3 & 4 & 5 & 6 & 7 & 8 & 9 & 10 \\
\hline \multirow[t]{2}{*}{ A, above } & -0.18 & -0.16 & -0.09 & -0.07 & -0.05 & -0.04 & -0.02 & -0.02 & -0.01 & -0.01 & -0.03 \\
\hline & $(9.04)^{\star \star}$ & $(12.29)^{\star \star}$ & $(7.09)^{\star \star}$ & $(5.73)^{\star \star}$ & $(4.45)^{\star \star}$ & $(3.41)^{\star *}$ & (1.49) & (1.64) & $(0.90)$ & (1.29) & $(2.40)^{\star}$ \\
\hline \multirow[t]{2}{*}{ BBB } & -0.14 & -0.12 & -0.08 & -0.07 & -0.04 & -0.03 & -0.02 & -0.02 & -0.01 & -0.01 & -0.01 \\
\hline & $(10.36)^{\star \star}$ & $(14.78)^{\star \star}$ & $(9.48)^{\star \star}$ & $(7.36)^{\star \star}$ & $(5.26)^{\star \star}$ & $(4.19)^{\star \star}$ & $(2.11)^{\star}$ & $(2.62)^{\star \star}$ & $(0.74)$ & $(1.42)$ & $(1.70)$ \\
\hline \multirow[t]{2}{*}{ BB, below } & -0.11 & -0.11 & -0.06 & -0.04 & -0.05 & -0.03 & -0.02 & -0.01 & -0.01 & -0.01 & -0.01 \\
\hline & $(12.45)^{\star \star}$ & $(14.67)^{\star \star}$ & $(9.54)^{\star \star}$ & $(5.88)^{\star \star}$ & $(7.36)^{\star \star}$ & $(4.67)^{\star \star}$ & $(3.32)^{\star \star}$ & (1.93) & $(2.09)^{\star}$ & $(2.05)^{\star}$ & $(2.27)^{\star}$ \\
\hline \multicolumn{12}{|c|}{ Panel B: Cumulative coefficient on the equity return } \\
\hline A, above & -0.18 & -0.34 & -0.43 & -0.51 & -0.56 & -0.60 & -0.62 & -0.63 & -0.64 & -0.66 & -0.68 \\
\hline BBB & -0.14 & -0.26 & -0.34 & -0.41 & -0.45 & -0.49 & -0.50 & -0.52 & -0.53 & -0.54 & -0.55 \\
\hline BB, below & -0.11 & -0.22 & -0.29 & -0.33 & -0.37 & -0.40 & -0.42 & -0.44 & -0.45 & -0.46 & -0.48 \\
\hline \multicolumn{12}{|c|}{ Panel C: Cumulative credit protection return response } \\
\hline time period & $(t+1, t+5)$ & $(t+2, t+6)$ & & $(\mathrm{t}+1, \mathrm{t}+10)$ & $(\mathrm{t}+2, \mathrm{t}+11)$ & & & & & & \\
\hline \multirow[t]{2}{*}{ A, above } & -0.44 & -0.29 & & -0.55 & -0.39 & & & & & & \\
\hline & $(3.65)^{\star \star}$ & $(2.42)^{\star \star}$ & & $(2.02)^{\star}$ & $(1.45)$ & & & & & & \\
\hline \multirow[t]{2}{*}{ BBB } & -0.37 & -0.25 & & -0.45 & -0.33 & & & & & & \\
\hline & $(4.46)^{\star \star}$ & $(2.90)^{\star \star}$ & & $(2.32)^{\star}$ & $(1.66)$ & & & & & & \\
\hline \multirow[t]{2}{*}{ BB, below } & -0.30 & -0.21 & & -0.39 & -0.29 & & & & & & \\
\hline & $(5.33)^{\star \star}$ & $(3.88)^{\star \star}$ & & $(3.40)^{\star \star}$ & $(2.63)^{\star \star}$ & & & & & & \\
\hline
\end{tabular}


Table 5: Response of the equity return to the credit protection return (daily)

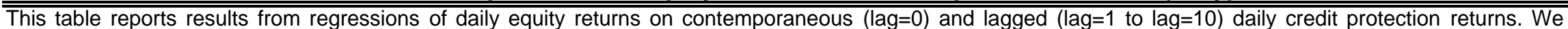
group observations into three groups using monthly S\&P credit rating. Regressions include firm fixed effects; to control for outliers, returns are winsorized at the $0.1 \%$ and the $99.9 \%$ levels. Panel A reports direct effects. We control for autocorrelation in the equity return by including the lagged equity return. Panel B reports cumulative effects which are calculated as the sum of the direct effects in Panel A. Panel C reports regressions of cumulative 5-day and 10-day equity returns on current credit protection returns, controlling for current equity returns. Standard errors are adjusted for heteroskedasticity and clustered by date. To control for overlapping observations in Panel $\mathrm{C}$, standard errors are also adjusted for autocorrelation. The t-statistics are reported in parentheses; $\star \star$ denotes significance at $1 \%$ and * denotes significance at $5 \%$.

\begin{tabular}{|c|c|c|c|c|c|c|c|c|c|c|c|}
\hline time period & 0 & 1 & 2 & 3 & 4 & 5 & 6 & 7 & 8 & 9 & 10 \\
\hline \multirow[t]{2}{*}{ A, above } & -0.033 & 0.001 & 0.000 & 0.002 & 0.001 & 0.006 & 0.001 & 0.001 & 0.002 & -0.001 & -0.004 \\
\hline & $(9.45)^{\star \star}$ & $(0.44)$ & $(0.18)$ & $(0.88)$ & $(0.41)$ & $(2.01)^{\star}$ & $(0.25)$ & $(0.26)$ & (1.05) & $(0.47)$ & $(1.46)$ \\
\hline \multirow[t]{2}{*}{ BBB } & -0.039 & -0.001 & 0.000 & 0.002 & 0.001 & 0.003 & -0.001 & -0.001 & 0.001 & -0.003 & -0.002 \\
\hline & $(10.77)^{\star \star}$ & $(0.20)$ & $(0.16)$ & $(0.76)$ & $(0.56)$ & $(1.27)$ & $(0.21)$ & $(0.24)$ & $(0.57)$ & $(1.23)$ & $(0.90)$ \\
\hline \multirow[t]{2}{*}{ BB, below } & -0.049 & -0.003 & -0.004 & -0.002 & 0.001 & 0.002 & 0.002 & 0.003 & -0.004 & -0.005 & -0.005 \\
\hline & $(12.48)^{\star \star}$ & $(1.08)$ & $(1.66)$ & $(0.62)$ & $(0.47)$ & $(0.60)$ & $(0.61)$ & $(0.87)$ & $(1.24)$ & $(1.54)$ & (1.78) \\
\hline \multicolumn{12}{|c|}{ Panel B: Cumulative coefficient on the credit protection return } \\
\hline A, above & -0.033 & -0.032 & -0.032 & -0.029 & -0.029 & -0.023 & -0.022 & -0.022 & -0.020 & -0.021 & -0.024 \\
\hline BBB & -0.039 & -0.040 & -0.040 & -0.038 & -0.037 & -0.034 & -0.034 & -0.035 & -0.034 & -0.037 & -0.039 \\
\hline BB, below & -0.049 & -0.053 & -0.057 & -0.059 & -0.057 & -0.055 & -0.054 & -0.051 & -0.055 & -0.060 & -0.065 \\
\hline \multicolumn{12}{|c|}{ Panel C: Cumulative equity return response } \\
\hline time period & $(\mathrm{t}+1, \mathrm{t}+5)$ & $(\mathrm{t}+2, \mathrm{t}+6)$ & & $(\mathrm{t}+1, \mathrm{t}+10)$ & $(t+2, t+11)$ & & & & & & \\
\hline \multirow[t]{2}{*}{ A, above } & 0.010 & 0.010 & & 0.009 & 0.009 & & & & & & \\
\hline & $(0.65)$ & $(0.66)$ & & $(0.34)$ & $(0.38)$ & & & & & & \\
\hline \multirow[t]{2}{*}{ BBB } & 0.004 & 0.005 & & -0.002 & 0.002 & & & & & & \\
\hline & $(0.22)$ & $(0.32)$ & & $(0.07)$ & $(0.07)$ & & & & & & \\
\hline \multirow[t]{2}{*}{ BB, below } & -0.007 & -0.002 & & -0.018 & -0.013 & & & & & & \\
\hline & $(0.31)$ & $(0.09)$ & & $(0.44)$ & $(0.33)$ & & & & & & \\
\hline
\end{tabular}


Table 6: Reaction of equity returns to large or positive credit protection returns

This table reports results from regressions of daily equity returns on contemporaneous (lag=0) and lagged (lag=1, 2) credit protection returns. Coefficients are estimated for two subsamples: 1) large credit protection returns (reported in Panel A) and 2) positive credit protection returns (reported in Panel B). Large credit protection returns are those above $2 \%$ in absolute value (close to $22 \%$ of observations). We group observations into three groups using monthly S\&P credit rating. Regressions include firm fixed effects. To control for outliers the data are winsorized at the $0.1 \%$ and the $99.9 \%$ levels. We control for autocorrelation in the credit protection return by including the lagged credit protection return. Standard errors are adjusted for heteroskedasticity and clustered by date. The t-statistics are reported in parentheses; ** denotes significance at $1 \%$ and ${ }^{*}$ denotes significance at $5 \%$.

\begin{tabular}{lccc}
\hline Panel A: Large credit protection returns & 0 & 1 & 2 \\
\hline lags & 0 & 0.001 & 0.001 \\
A, above & -0.033 & $(0.52)$ & $(0.23)$ \\
& $(9.26)^{\star \star}$ & 0.000 & 0.000 \\
BBB & -0.038 & $(0.04)$ & $(0.06)$ \\
& $(10.40)^{\star \star}$ & -0.003 & -0.004 \\
BB, below & -0.046 & $(0.83)$ & $(1.66)$ \\
& $(11.74)^{\star \star}$ & & \\
\hline Panel B: Positive credit protection returns & & 2 \\
\hline lags & 0 & 1 & 0.001 \\
\hline A, above & -0.034 & 0.000 & $(0.32)$ \\
& $(6.01)^{\star \star}$ & $(0.04)$ & 0.003 \\
BBB & -0.038 & -0.002 & $(0.64)$ \\
& $(6.62)^{\star \star}$ & $(0.56)$ & -0.002 \\
BB, below & -0.026 & 0.000 & $(0.55)$ \\
\hline
\end{tabular}


Table 7: Response of the credit protection return to the equity return (weekly)

\begin{tabular}{|c|c|c|c|c|c|c|}
\hline \multirow{2}{*}{\multicolumn{7}{|c|}{$\begin{array}{l}\text { This table reports results from regressions of weekly credit protection returns ol } \\
\text { lagged (lag= } 1 \text { to lag }=5 \text { ) weekly equity returns. We group observations into three } \\
\text { rating. Regressions include firm fixed effects; to control for outliers the data are } \\
99.9 \% \text { levels. Panel A reports direct effects. We control for autocorrelation in the cr } \\
\text { the lagged credit protection return. Panel B reports cumulative effects which are ca } \\
\text { effects in Panel A. Standard errors are adjusted for heteroskedasticity and clust } \\
\text { reported in parentheses; }{ }^{\star \star} \text { denotes significance at } 1 \% \text { and }{ }^{*} \text { denotes significance at } \\
\text { Panel A: Regression of the credit protection return on the equity return }\end{array}$}} \\
\hline & & & & & & \\
\hline time period & 0 & 1 & 2 & 3 & 4 & 5 \\
\hline \multirow[t]{2}{*}{ A, above } & -0.44 & -0.27 & -0.10 & -0.11 & -0.06 & -0.04 \\
\hline & $(5.94)^{\star \star}$ & $(7.55)^{\star \star}$ & $(2.47)^{\star}$ & $(2.90)^{\star \star}$ & $(1.90)$ & $(1.12)$ \\
\hline BBB & $\begin{array}{c}-0.35 \\
(7.50)^{\star \star}\end{array}$ & $\begin{array}{c}-0.21 \\
(7.75)^{\star \star}\end{array}$ & $\begin{array}{c}-0.09 \\
(3.19)^{\star \star}\end{array}$ & $\begin{array}{c}-0.11 \\
(4.23)^{\star \star}\end{array}$ & $\begin{array}{c}-0.07 \\
(2.65)^{\star \star}\end{array}$ & $\begin{array}{l}-0.04 \\
(1.41)\end{array}$ \\
\hline BB, below & $\begin{array}{c}-0.29 \\
(8.47)^{\star \star}\end{array}$ & $\begin{array}{c}-0.20 \\
(10.03)^{\star \star}\end{array}$ & $\begin{array}{c}-0.08 \\
(4.01)^{\star \star}\end{array}$ & $\begin{array}{c}-0.04 \\
(2.39)^{*}\end{array}$ & $\begin{array}{c}-0.08 \\
(3.63)^{\star \star}\end{array}$ & $\begin{array}{l}-0.03 \\
(1.68)\end{array}$ \\
\hline \multicolumn{7}{|c|}{ Panel B: Cumulative coefficient on the equity return } \\
\hline A, above & -0.44 & -0.72 & -0.82 & -0.93 & -0.99 & -1.04 \\
\hline BBB & -0.35 & -0.56 & -0.65 & -0.76 & -0.83 & -0.87 \\
\hline $\mathrm{BB}$, below & -0.29 & -0.49 & -0.58 & -0.62 & -0.70 & -0.73 \\
\hline
\end{tabular}


Table 8: Response of the equity return to the credit protection return (weekly)

This table reports results from regressions of weekly equity returns on contemporaneous (lag=0) and lagged (lag=1 to lag=5) weekly credit protection returns. We group observations into three groups using monthly S\&P credit rating. Regressions include firm fixed effects; to control for outliers the data are winsorized at the $0.1 \%$ and the $99.9 \%$ levels. Panel A reports direct effects. We control for autocorrelation in the equity return by including the lagged equity return. Panel $B$ reports cumulative effects which are calculated as the sum of the direct effects in Panel $A$. Standard errors are adjusted for heteroskedasticity and clustered by date. The t-statistics are reported in parentheses; ** denotes significance at $1 \%$ and * denotes significance at $5 \%$.

\begin{tabular}{|c|c|c|c|c|c|c|}
\hline time period & 0 & 1 & 2 & 3 & 4 & 5 \\
\hline \multirow[t]{2}{*}{ A, above } & -0.063 & 0.008 & 0.000 & 0.002 & 0.006 & -0.005 \\
\hline & $(7.03)^{\star \star}$ & (0.98) & $(0.06)$ & $(0.31)$ & (1.15) & $(0.95)$ \\
\hline \multirow[t]{2}{*}{ BBB } & -0.073 & 0.004 & -0.001 & 0.005 & 0.002 & -0.004 \\
\hline & $(8.25)^{\star \star}$ & $(0.68)$ & $(0.18)$ & $(0.85)$ & $(0.32)$ & (0.60) \\
\hline \multirow[t]{2}{*}{ BB, below } & -0.095 & -0.003 & -0.012 & -0.007 & 0.001 & 0.004 \\
\hline & $(10.00)^{\star \star}$ & $(0.41)$ & (1.66) & $(0.90)$ & $(0.15)$ & $(0.54)$ \\
\hline \multicolumn{7}{|c|}{ Panel B: Cumulative coefficient on the credit protection return } \\
\hline A, above & -0.063 & -0.055 & -0.055 & -0.054 & -0.048 & -0.053 \\
\hline BBB & -0.073 & -0.069 & -0.070 & -0.065 & -0.063 & -0.067 \\
\hline BB, below & -0.095 & -0.098 & -0.110 & -0.117 & -0.116 & -0.112 \\
\hline
\end{tabular}


Table 9: Determinants of CDS fractional response

This table reports results from regressions of the CDS fractional response on explanatory variables. The fractional response is the ratio of the credit protection return at $t$ and the return from to t $t+11$. If the response from $t$ to $t+11$ is of the opposite sign compared to the date $t$ response we set the fractional response equal to 0 . If the date $t$ response is larger than the response from t to $t+11$ we set the fractional response equal to 1 . Low Depth an indicator for an issuer in the lowest quartile of the number of independent CDS quotes for a calendar quarter. Abs(equity return) is the absolute value of the equity return on date $t$. In some specifications, these two explanatory variables are interacted with an indicator, Large Return, for an observation with abs(equity return) on date $\mathrm{t}$ in the top $10 \%$ of the distribution. All regressions include firm fixed effects. If an interaction with the Large Return indicator is included, then the specification also controls for the direct effect of Large Return (unreported). To control for outliers, returns are winsorized at the $0.1 \%$ and $99.9 \%$ levels. Standard errors are adjusted for heteroskedasticity and clustered by date. The t-statistics are reported in parentheses; ** denotes significance at $1 \%$ and * denotes significance at $5 \%$.

\begin{tabular}{|c|c|c|c|c|c|}
\hline \multicolumn{6}{|c|}{ Fraction of credit protection return response from $t$ to $t+11$ that occurs at $t$} \\
\hline & (1) & $(2)$ & (3) & $(4)$ & $(5)$ \\
\hline \multirow[t]{2}{*}{ Low Depth } & -0.0146 & & -0.0155 & & -0.0154 \\
\hline & $(9.09)^{\star \star}$ & & $(9.65)^{\star \star}$ & & $(9.58)^{\star \star}$ \\
\hline \multirow[t]{2}{*}{ Abs(equity return) } & & 0.0045 & 0.0047 & 0.0021 & 0.0022 \\
\hline & & $(9.42)^{\star \star}$ & $(9.80)^{\star \star}$ & $(2.75)^{\star \star}$ & $(3.00)^{\star \star}$ \\
\hline \multirow[t]{2}{*}{ Abs(equity return) * Large Return } & & & & 0.0068 & 0.0067 \\
\hline & & & & $(6.37)^{\star \star}$ & $(6.29)^{\star \star}$ \\
\hline Observations & 723,772 & 723,772 & 723,772 & 723,772 & 723,772 \\
\hline
\end{tabular}


Table 10: Response to earnings announcements

$\overline{\text { This table reports earnings surprises (Panel A), and credit protection return and stock market return around earnings announcements (Panel B, C). Earnings }}$ surprises are grouped into 10 groups -- 3 negative surprise groups, zero, and 6 positive surprise groups. To control for outliers, returns are winsorized at the $0.1 \%$ and $99.9 \%$ levels. Standard errors are adjusted for heteroskedasticity. The t-statistics are reported in parentheses; ${ }^{\star}$ denotes significance at $1 \%$ and ${ }^{*}$ denotes significance at $5 \%$.

\begin{tabular}{|c|c|c|c|c|c|c|c|c|c|c|}
\hline \multicolumn{11}{|l|}{ Panel A: Earnings surprise } \\
\hline Surprise group & 1 & 2 & 3 & 4 & 5 & 6 & 7 & 8 & 9 & 10 \\
\hline Sign of surprise & neg & neg & neg & zero & pos & pos & pos & pos & pos & pos \\
\hline Mean of surprise & $-1.89 \%$ & $-0.15 \%$ & $-0.04 \%$ & $0.00 \%$ & $0.02 \%$ & $0.05 \%$ & $0.09 \%$ & $0.15 \%$ & $0.26 \%$ & $1.00 \%$ \\
\hline Number of observations & 958 & 964 & 967 & 1,376 & 1256 & 1266 & 1261 & 1273 & 1266 & 1258 \\
\hline \multicolumn{11}{|c|}{ Panel B: Credit protection return $(\mathrm{t}-2, \mathrm{t}+2)$} \\
\hline Mean & $2.84 \%$ & $2.09 \%$ & $1.09 \%$ & $0.94 \%$ & $0.07 \%$ & $-0.04 \%$ & $0.02 \%$ & $0.03 \%$ & $-0.23 \%$ & $-0.72 \%$ \\
\hline t-statistic & $(6.13)^{\star \star}$ & $(5.54)^{\star \star}$ & $(2.84)^{\star \star}$ & $(2.87)^{\star \star}$ & $(0.23)$ & $(0.13)$ & $(0.05)$ & $(0.11)$ & $(0.79)$ & $(2.52)^{\star}$ \\
\hline \multicolumn{11}{|c|}{ Panel C: Equity return $(\mathrm{t}-2, \mathrm{t}+2)$} \\
\hline Mean & $-3.20 \%$ & $-2.43 \%$ & $-1.45 \%$ & $-0.44 \%$ & $0.10 \%$ & $0.69 \%$ & $1.41 \%$ & $2.10 \%$ & $2.45 \%$ & $3.57 \%$ \\
\hline t-statistic & $(12.34)^{\star \star}$ & $(12.79)^{\star \star}$ & $(8.16)^{\star \star}$ & $(2.63)^{\star \star}$ & $(0.71)$ & $(4.56)^{\star \star}$ & $(8.78)^{\star \star}$ & $(12.90)^{\star \star}$ & $(14.31)^{\star \star}$ & $(16.41)^{\star \star}$ \\
\hline
\end{tabular}




\section{Table 11: Equity returns and credit protection returns during and outside earnings annoucements}

Panel A reports results from regressions of credit protection returns on equity returns. We report results from regressing contemporaneous ( $t$ ), next day ( $t+1)$ and subsequent cumulative 5 -day $(t+2, t+6)$ and 10-day $(t+2, t+11)$ credit protection returns on date t equity returns. Panel $B$ reports results from regressions of equity returns on credit protection returns. We control for the autocorrelation in credit protection returns (or equity returns) by including the lagged dependent variable (at time $\mathrm{t}$ ) in all but the contemporaneous regressions. We allow for different coefficients when time $t$ is during earnings announcements and report the difference in coefficients. Regressions include firm fixed effects. To control for outliers, returns are winsorized at the $0.1 \%$ and the $99.9 \%$ levels. Standard errors are adjusted for heteroskedasticity and clustered by date. For regressions with overlapping observations, the standard errors are also adjusted for autocorrelation of the residuals. The t-statistics are reported in parentheses; ** denotes significance at $1 \%$ and ${ }^{*}$ denotes significance at $5 \%$.

\begin{tabular}{|c|c|c|c|c|c|c|}
\hline time period & $t-->t$ & $t-->t+1$ & $\mathrm{t}-->(\mathrm{t}+2, \mathrm{t}+6)$ & $t-->(t+2, t+11)$ & $(\mathrm{t}-5, \mathrm{t}-1)-->t$ & $(\mathrm{t}-6, \mathrm{t}-2)-->\mathrm{t}$ \\
\hline No earnings announcement at $t$ & $\begin{array}{l}-0.136 \\
(11.51)^{\star *}\end{array}$ & $\begin{array}{c}-0.129 \\
(16.52)^{\star \star}\end{array}$ & $\begin{array}{l}-0.255 \\
(3.27)^{\star \star}\end{array}$ & $\begin{array}{l}-0.348 \\
(2.00)^{\star}\end{array}$ & $\begin{array}{c}-0.071 \\
(20.99)^{\star \star}\end{array}$ & $\begin{array}{c}-0.048 \\
(15.15)^{\star \star}\end{array}$ \\
\hline Earnings announcement at $t$ & $\begin{array}{l}-0.210 \\
(9.59)^{\star \star}\end{array}$ & $\begin{array}{l}-0.124 \\
(8.37)^{\star \star}\end{array}$ & $\begin{array}{l}-0.165 \\
(4.99)^{\star \star}\end{array}$ & $\begin{array}{l}-0.213 \\
(4.64)^{\star \star}\end{array}$ & $\begin{array}{l}-0.116 \\
(6.62)^{\star \star}\end{array}$ & $\begin{array}{l}-0.100 \\
(6.37)^{\star \star}\end{array}$ \\
\hline Difference & $\begin{array}{l}-0.074 \\
(3.35)^{\star \star}\end{array}$ & $\begin{array}{l}0.005 \\
(0.32)\end{array}$ & $\begin{array}{l}0.090 \\
(0.84)\end{array}$ & $\begin{array}{l}0.135 \\
(0.62)\end{array}$ & $\begin{array}{l}-0.046 \\
(2.70)^{\star \star}\end{array}$ & $\begin{array}{l}-0.052 \\
(3.44)^{\star \star}\end{array}$ \\
\hline \multicolumn{7}{|l|}{$\mathrm{R}^{2}$ (within) } \\
\hline $\begin{array}{l}\text { Outside earnings announcement } \\
\text { During earnings announcement }\end{array}$ & $\begin{array}{l}0.50 \% \\
3.16 \%\end{array}$ & $\begin{array}{l}0.45 \% \\
1.56 \%\end{array}$ & & & & \\
\hline
\end{tabular}

\begin{tabular}{|c|c|c|c|c|c|c|}
\hline time period & $t-->t$ & $t-->t+1$ & $\mathrm{t}-->(\mathrm{t}+2, \mathrm{t}+6)$ & $t-->(t+2, t+11)$ & $(\mathrm{t}-5, \mathrm{t}-1)-->\mathrm{t}$ & $(\mathrm{t}-6, \mathrm{t}-2)-->\mathrm{t}$ \\
\hline \multirow[t]{2}{*}{ No earnings announcement at t } & -0.037 & 0.000 & 0.005 & 0.000 & 0.000 & 0.000 \\
\hline & $(11.96)^{\star \star}$ & $(0.20)$ & $(0.35)$ & $(0.00)$ & (0.18) & (0.31) \\
\hline \multirow[t]{2}{*}{ Earnings announcement at $\mathrm{t}$} & -0.147 & -0.011 & -0.020 & -0.014 & 0.003 & 0.001 \\
\hline & $(11.20)^{\star \star}$ & $(1.27)$ & $(1.12)$ & $(0.72)$ & $(0.51)$ & $(0.17)$ \\
\hline \multirow[t]{2}{*}{ Difference } & -0.111 & -0.011 & -0.025 & -0.013 & 0.003 & 0.001 \\
\hline & $(8.48)^{\star \star}$ & $(1.27)$ & $(0.50)$ & $(0.17)$ & $(0.50)$ & $(0.12)$ \\
\hline \multicolumn{7}{|l|}{$\mathrm{R}^{2}$ (within) } \\
\hline Outside earnings announcement & $0.50 \%$ & $0.00 \%$ & & & & \\
\hline During earnings announcement & $3.14 \%$ & $0.02 \%$ & & & & \\
\hline
\end{tabular}




\section{Table 12: Fractional response and earnings announcements}

This table compares the CDS fractional response during earnings announcements to the fractional response outside earnings announcements. The fractional response is the ratio of the credit protection return at $t$ and the return from $t$ to $t+11$. If the response from to to $t 11$ is of the opposite sign compared to the date $t$ response we set the fractional response equal to 0 . If the date $t$ response is larger than the response from $t$ to $t+11$ we set the fractional response equal to 1 . We report the average fractional response for non-earnings-announcement days, those with an earnings announcement, and the difference between the two fractional responses. We report results for the full sample and for a placebo sample. The placebo sample is constructed as follows: for each earnings announcement we find four days with similarly-sized equity returns outside of earnings announcement windows (more than 15 trading days before or after an earning announcement). We only include these observations along with the earnings announcement observations. To control for outliers, returns are winsorized at the $0.1 \%$ and $99.9 \%$ levels. Standard errors are adjusted for heteroskedasticity and clustered by date. The t-statistics are reported in parentheses; ${ }^{*}$ denotes significance at $1 \%$ and * denotes significance at $5 \%$.

\begin{tabular}{lcc}
\hline \multicolumn{3}{c}{ Fraction of credit protection return response from $\mathrm{t}$ to $\mathrm{t}+11$ that occurs at $\mathrm{t}$} \\
\hline & comparison to full sample & comparison to placebo sample \\
\hline No earnings announcement at $\mathrm{t}$ & 0.165 & 0.171 \\
& $(123.24)^{\star \star}$ & $(74.53)^{\star \star}$ \\
Earnings announcement at $\mathrm{t}$ & 0.191 & 0.191 \\
& $(48.90)^{\star \star}$ & $(48.90)^{\star \star}$ \\
Difference & 0.026 & 0.019 \\
& $(6.93)^{\star \star}$ & $(4.41)^{\star \star}$ \\
\hline
\end{tabular}

